\title{
A Study of the Effect of Iron and Silicon As Cement Components on Cerebral and Cerebellar cortices of Albino Rats and the Possible Protective Role of Omega 3: A Toxicological and Histological Study
}

\author{
Abeer Abd Elmoneim Sheta' and Noha Mahmoud Zahran² \\ ${ }^{1}$ Forensic Medicine and Clinical Toxicology Department. \\ ${ }^{2}$ Histology and Cell Biology Department. \\ Faculty of Medicine, University of Alexandria, Alexandria, Egypt.
}

\begin{abstract}
Introduction Cement industry generates dust during its production. The main route of entry of cement dust particles in the body is the respiratory tract and / or the gastrointestinal tract by inhalation or swallowing, producing both respiratory and non-respiratory systems involvement. Content of Portland cement is a mixture of elements that include iron and silicon. Yet, there is a lack of the studies concerned with the effects of cement on different organs in humans or animals. Therefore, the aim of the present study was to investigate the effect of two of cement components (silicon and iron) on brain tissues and the possible protective effect of omega-3.

Material and methods fifty male adult albino rats were divided into three groups; Group I (control group), Group II (treated group) that was subdivided into three subgroups; subgroup IIa, received iron as ferrous chloride, subgroup IIb, received silicon as sodium silicate and subgroup IIc, received both elements orally for two months and Group III (protected group) received iron and silicon, simultaneously with omega- 3. Energy Dispersive X-ray Spectrometry (EDX) analysis was done. Frontal cerebral \& cerebellar cortices were subjected for biochemical oxidative assay. Histological study and immunohistochemical staining for Glial fibrillary acidic protein (GFAP) were performed as well as morphometric study.

Results cerebral \& cerebellar cortices of treated rats (subgroup IIc) showed peaks for iron and silicon. The profile of oxidative stress markers, in group (II), revealed significantly decreased antioxidant enzymes activity, superoxide dismutase (SOD) and catalase (CAT), while malondialdehyde (MDA) level increased significantly as compared with control group. Histological findings of cerebral and cerebellar cortices revealed different degrees of degenerated nerve cells, tissue vacuolation, and degenerated neuropil in group II. Immunohistochemial results showed marked proliferation of astrocytes. The co-administration of omega-3 (group III) showed significant increase of both SOD and CAT activities and significant decrease of MDA. Marked preservation of cerebral and cerebellar cortical tissues was noticed. Conclusion The present work revealed the hazardous effect of cement component (iron and silicon) on cerebral \& cerebellar cortices of albino rats. The role of protective effect of omega-3 might find a clinical application against the hazardous effect among the exposed workers. Further studies are needed to magnitude the problem on health.
\end{abstract}

\section{Introduction}

P rolonged exposure to cement dust has a harmful nature of the manufacturing process. The pollutants in the cement industry are emitted from various production processes such as the raw material, crusher, rotary kiln, cranes, mills, storage silos and packing section, etc.,( Al-Neaimi et al.,2001; Mwaiselage et al., 2006).
Cement industry generates dust during its production making and the whole respiratory tract is a target for cement deposition. The main route of entry of cement dust particles in the body is the respiratory tract and / or the gastrointestinal tract by inhalation or swallowing respectively. (Al-Neaimi et al.,2001; Manjula et al.,2013;). 
The cement dust may enter the systemic circulation through the gastrointestinal tract by swallowing, and in turn reach all organs of the body. Eventually, it affects micro-structure and physiological performance. Therefore, it may produce various clinical disorders which include both respiratory and non-respiratory systems involvement (Meo, 2004).

Contents of Portland cement include mixtures of calcium oxide-62- $66 \%$, silicon oxide-19-22\%, Aluminium tri oxide-4-8\%, ferric oxide-2-5\%, Magnesium oxide-1-2\% and also contain selenium, Thallium, and other impurities (Short and Petsonk, 1996).

Iron, is known to play a vital role in several essential metabolic processes, thus being considered as fundamental for life. Metal ion homeostasis is maintained through highly regulated mechanisms of uptake, storage, and secretion (Mills et al., 2010). On the other hand, various investigators suggested that iron is an important factor in different chronic neurodegenerative diseases (Johnstone and Milward, 2010b; Jomova and Valko, 2011; Mesquita et al., 2012).

Silicon is one of the most abundant elements on the earth. Various studies have recognized the role of silicon in a variety of tissues processes such as bone formation and calcification (Jugdaohsingh, 2007; Martin 2007; Macdonald et al., 2012; Price et al., 2013).

However, exposure to the dusts of silica is a widespread occupational hazard, with the highest exposures in construction, mining, and cement production, previous reviews have extensively documented that silica is a risk factor for Systemic lupus erythematosus and other systemic autoimmune diseases (Calvert et al.,2003; Parks and Cooper, 2006; Cooper et al., 2008).

Most of the researches described the respiratory hazardous of cement dust. Yet, there is a lack of the studies concerned with general health effects on different organs in human or animal.

Different studies demonstrated the crucial role of omega-3 polyunsaturated fatty acids ( $n-3$ PUFAs) in brain health. The valuable effects of ( $n-3$ PUFA) have been recognised in a diversity of central nervous system disorders, including schizophrenia, depression and Alzheimer's disease, despite of major differences between them. Omega-3 is particularly used in areas in which therapeutic alternatives are limited (MichaelTitus, 2007).

The aim of the present study was to investigate the toxic effect of cement components (silicon and iron) on brain tissues (cerebral and cerebellar cortices) of the adult male albino rats and protective effect of omega - 3 was also assessed.

\section{Material and methods Chemicals}

- Iron in the form of ferrous chloride, $\mathrm{Fe} \mathrm{Cl}_{2}$, (crystals) was purchased from oxford laboratory (India)
- Silicon in the form of sodium silicate $\mathrm{Na} \mathrm{SiO}_{2}$ (powder) was purchased from (Sigma-Aldrich Chemistry)

- Omega-3 fatty acid (oil) was purchased from (Sigma-Aldrich)

\section{Animals and treatments}

Fifty male albino rats weighing 150-200 gm were purchased from the Animal House at the Faculty of Medicine, Alexandria University, Egypt. Animals were housed in cages at room temperature and on a $12 \mathrm{~h}$ light-darkness cycle. The animals had free access to diet and water ad libitum.

The approval of this study was obtained from the Research Ethics Committee of the Faculty of Medicine, Alexandria University.

After one week acclimatization, the rats were randomly divided into three groups:

1. Group I (control group) (10 rats): rats of this group were divided into 2 subgroups; each contains five rats; subgroup a, that received normal saline $(0.9 \%) \mathrm{NaCl}$ for two months and subgroup $b$, that received Omega- 3 $(0.35 \mathrm{mg} / \mathrm{g})$ for two months (Rakic, 2002). The rout of administration for all groups was by gavage.

2. Group II (treated group): included 30 rats that were further subdivided into three equal subgroups, each of 10 rats

- Subgroup IIa (iron treated): rats of this group received iron $(0.00065$ $\mathrm{mg} / \mathrm{g}$ ) as ferrous chloride, $\mathrm{Fe}_{2}$, for two months (Abd El-Rahman et al.,2011)

- Subgroup IIb (silicon treated): rats of this group received silicon $(0.0013$ $\mathrm{mg} / \mathrm{g}$ ) as of sodium silicate, $\mathrm{Na} \mathrm{SiO}_{2}$, for two months (Abd El-Rahman et al.,2011).

- Subgroup IIc (combined iron and silicon treated): rats of this group received iron ions $(0.00065 \mathrm{mg} / \mathrm{g})$ as ferrous chloride $\mathrm{Fe} \mathrm{Cl}_{2}$ and silicon as sodium silicate $\mathrm{Na} \quad \mathrm{SiO}_{2} \quad(0.0013$ $\mathrm{mg} / \mathrm{g}$ ), for two months separating time interval $30 \mathrm{~min}$ between each administration (Abd El-Rahman et al.,2011).

3. Group III (protected group) (10 rats): rats of this group received iron $(0.00065 \mathrm{mg} / \mathrm{g})$ as ferrous chloride $\left(\mathrm{Fe} \mathrm{Cl}_{2}\right)$ and silicon as sodium silicate $\mathrm{Na} \mathrm{SiO}_{2}(0.0013 \mathrm{mg} / \mathrm{g})$, separating time interval $30 \mathrm{~min}$ between each administration. Simultaneously, the rats received omega- $3(0.35 \mathrm{mg} / \mathrm{g})$ for two month (Abd El-Rahman et al., 2011; Rakic, 2002).

Twenty four hours after the end of the experimental period, the rats were sacrificed by light inhalation ether anesthesia and the skull was opened; the frontal cerebral and cerebellar cortices of all animals were dissected out carefully. 
The dissected tissues were subjected for EDX analysis, biochemical oxidative stress assay and histological study.

\section{Energy Dispersive X-ray Spectrometry (EDX) analysis}

Fresh tissues from the cerebral and cerebellar cortices were taken for detection of iron and silicon in the tissue samples, and plotting the results on a graph using Energy Dispersive X-ray Spectrometry (EDX) connected to scanning microscope screen (JEOL, Germany) at the Faculty of Science, electron microscope unit, Alexandria University.

\section{Biochemical oxidative stress assay}

The tissues used for biochemical oxidative stress assay was homogenized in ice cold of phosphate buffer $(\mathrm{PH}$ : 7.4 ) in teflon glass homogenizer. The homogenate was centrifuged at $13.000 \mathrm{xg}$ for $30 \mathrm{~min}$ to obtain supernatant that was used for enzymatic assay. Superoxide dismutase (SOD) enzyme activity performed according to Misra and Fridovich (1972). Catalase activity was assayed as the method of Aebi et al (1974). The enzymatic activities were expressed as $\mathrm{U} / \mathrm{mg}$ protein. Tissue homogenate was used for lipid peroxidation product (Malondialdehyde, MDA ) determination as by procedure described by Ohkawa et al., (1979). The values were expressed as nmol of MDA / gm tissue.

\section{Histological study}

For histological study the tissues was fixed in $10 \%$ formalin and processed for light microscopic study to obtain paraffin sections of $5 \mu \mathrm{m}$ thickness. Sections were stained as follows:

1- H\&E staining (Bancroft and Gamble, 2005).

2- Immunohistochemical staining for Glial fibrillary acidic protein (GFAP) to demonstrate astrocytes.

Immunohistochemical stain: Serial paraffin sections of $5 \mu \mathrm{m}$ thickness were placed on positively charged glass slides. Deparaffinization and hydration of sections were carried out. The endogenous peroxidase activity was blocked with $10 \%$ hydrogen peroxide for $10 \mathrm{~min}$. To unmask the antigenic sites, sections were placed in $0.01 \mathrm{~mol} / \mathrm{l}$ citrate buffer $(\mathrm{pH}=6)$ in the microwave for 5 min. The slides were washed for $5 \mathrm{~min}$ in phosphate buffered saline (PBS) at $\mathrm{pH} 7.4$ and then incubated in $1 \%$ bovine serum albumin (BSA) dissolved in PBS for $30 \mathrm{~min}$ at $37^{\circ} \mathrm{C}$ to prevent nonspecific background staining. Two drops of ready-to-use primary antibody were applied to sections, except for negative controls, and they were incubated for one hour at room temperature. Half of the sections were treated with Glial fibrillary acidic protein (GFAP) (Ab-1, clone GA-5 mouse monoclonal antibody). The slides were rinsed with PBS and a few drops of biotinylated goatpolyvalent secondary antibody were applied for 10 min. To detect the reaction, the slides were incubated in 3,3-diaminobenzidene (DAB) for $15 \mathrm{~min}$ and counter stained by hematoxylin, dehydrated, cleared, and mounted by DPX.
Note that negative control sections were obtained using PBS without the primary antibody.

\section{3- Morphometric study}

The morphometric and statistical study was conducted using a computerized image analyzer system software (Leica Q 500 MCO; Leica, Germany) connected to a camera attached to a Leica universal microscope at the Histochemistry and Cell Biology Department, High Research Institute, Alexandria University. Sections from each slide (cerebellum) of five different animals from each group stained with $\mathrm{H} \& \mathrm{E}$ in 10 non overlapping fields were examined. The numbers of normal Purkinje cells (according to their shape, vesicular nucleus, prominent nucleolus and acidophilic cytoplasm) were counted. The measurement was made using an objective lens of $\times 20$ magnification.

Also, the number of astrocytes per high-power field $(\times 40)$ was counted using GFAP-stained sections. Five fields from three serial sections of five different rats from each group were examined by means of a high-power lens $(\times 40)$ using the image analyzer.

\section{Statistical analysis}

Statistical analysis was done using Statistical Package for Social Sciences (SPSS/version 20) software. The data was analyzed using ANOVA-test was used for parametric data followed by post hock test between each two groups. The level of significant was 0.05. Results are expressed as mean values \pm SD.

\section{Results:}

\section{Energy Dispersive X-ray Spectrometry (EDX) analysis}

Samples of cerebral cortex and cerebellum of control rats showed no peaks for iron or silicon. On the other hand, EDX spectra of the samples treated with iron and silicon (subgroup IIc), showed the peaks for iron and silicon. Other elements, such as calcium $(\mathrm{Ca})$, sulfur $(\mathrm{S})$, sodium $(\mathrm{Na})$, potassium $(\mathrm{K})$ and phosphorus $(\mathrm{P})$ were detected as well (Fig.1)

\section{Biochemical oxidative stress assay (Table1\&Fig.2):}

The profile of oxidative stress markers are presented in table (1) and Figure (2). The activity of antioxidant enzymes, superoxide dismutase (SOD) and catalase (CAT), significantly reduced in group (II) in both cerebral cortex and cerebellum as compared with control group (Ia), except, CAT activity in group IIb in cerebellum tissue showed insignificant decrease.

The co-administration of omega-3 (group III) showed significant increase of both SOD and CAT activities when compared with iron and silicon (IIc) treated group. Yet, it was still significantly lower than control level.

On the other hand, malondialdehyde (MDA) content increased significantly in both cerebral cortex and cerebellum in rats of group (II) when compared with control group (Ia). Omega-3 administration significantly reduced lipid peroxidation when it was concurrently administered with both iron and silicon. 
In cerebral cortex, MDA was still significantly higher than control level.

Histological results:

\section{H\&E staining}

- Group I (control groups)

In H\&E-stained sections, the frontal cortex motor area of subgroup Ia and subgroup Ib, were covered by pia matter containing blood vessels. Six layers were identified in the cerebral cortex; outer molecular layer, external granular layer, external pyramidal layer, inner granular layer, inner pyramidal, and the pleomorphic layer (Fig. 3a). The pyramidal cells of the pyramidal layer showed vesicular nuclei, acidophilic cytoplasm, and long apical dendrites, whereas the granular cells, perineural neuroglia cells, and blood capillaries were scattered among neurons. The granular cells showed large open face nuclei with prominent nucleolus and little cytoplasm. The pink-stained background, the neuropil, appeared homogenous pale acidophilic background made by a mat of neuronal and glial cell processes (Fig. 3b).

The cerebellum of control subgroups showed the characteristic appearance the cortex exhibited regular pial surface, the outer molecular layer, a single layer of pear shaped of Purkinje cells and inner most granular layer (Fig 4a). The molecular layer was formed of few small stellate cells located superficially and basket cells were found in the deeper parts near Purkinje cell bodies. The Purkinje cell layer was observed to be arranged in a single row along the outer margin of the granular layer. It consisted of large Purkinje neurons with clear vesicular nuclei, prominent nucleoli, and a acidophilic cytoplasm, the nuclei of Bergmann astrocytes that unsheathes the Purkinje were also seen (Figs $4 \mathrm{a} \& \mathrm{~b}$ ). The granular layer was composed of tightly packed small rounded cells with deeply stained nuclei and also interspersed among these cells were clear spaces (glomerulus or cerebellar islands), where synapses occur between axons entering the cerebellum from outside and dendrites of granule cells (Fig.4b ).

\section{- Group II (treated group)}

Light microscopic examination of rat motor cortical area of subgroup II a (Fig5a) showed ill-defined cortical layers with multiple vacuolations, an apparent increase in the number of the apoptotic pyramidal and granular cells as compared with control subgroups. The apoptotic cells were shrunken and surrounded by halos and exhibited condensed darkly stained nuclei (Fig.5b). Rats of subgroup IIb, revealed multiple vacuolation, dilatation of blood vessels and shrunken pyramidal and granular cells but to a lesser degree than from subgroup IIa(Fig.5c\&d ). These changes were more evident in addition to massive destruction of cortical tissue and degenerated neuropil with areas dense staining in subgroup IIc (Figs $6 \mathrm{a} \& \mathrm{~b}$ ).

The cerebellum showed a less affection than the cerebral cortex with noticed reduction in the number of normal Purkinje cells. In treated subgroup IIa the Purkinje neurons showed an irregular outline, a darkly stained cytoplasm and hardly identified nuclei, some Bergmann cells appeared with dense nuclei and vacuolated cytoplasm. The pial surface were thickened (Fig 7 a). Prominent perineuronal spaces were observed in the molecular layer around both basket and stellate cell. Vascular congestion with wide perivascular spaces or swelling and also hemorrhage in the granular layer and white matter were observed. The cerebellar cortex of the treated subgroup IIb exhibited focal degenerated Purkinje cells whereas the granular layer appeared unaffected (Fig7c). In combined subgroup IIc the cerebellum was markedly affected, few Purkinje cells were hardly detected with darkly stained nuclei and a darkly stained cytoplasm surrounded by wide perineural spaces and few degenerated Bergmann cells. Vacuolated molecular layer with dense nuclei and thickened pial surface are seen, revealing gliosis. The granular layer showed multiple dense nuclei (Fig. 8)

- Group III: (protected group)

Light microscoic examination of rat motor cortical area of protected group revealed improvement of the different layers of the cerebral cortex 
in comparison with treated subgroups. Some of pyramidal cells showed normal appearance with vesicular nuclei and acidophilic cytoplasm while other cells still degenerated (Fig; 9a\&b). The neuropil appeared with microscopic vacuoles (Fig 9 b)

The cerebellum was markedly improved and preserved with the intake of omega-3, demonstrated by preservation of Purkinje cell layer almost all the cells have the vesicular nuclei and prominent nucleolus. On the other hand some cells were affected (Figs. $10 \mathrm{a} \& \mathrm{~b})$

2. Immunohistochemical staining for Glial fibrillary acidic protein (GFAP) to demonstrate astrocytes

Immunohistochemical staining for GFAP in control cerebral cortex showed GFAP-positive astrocytes; they appeared small, fine reddish brown with thin few processes, in the granular and molecular layers almost around blood capillaries and beneath the pia matter (Fig11)

GFAP immunostaining of the control cerebellum showed faint immunoreactions of astrocytes in the molecular layer, granular layer and around Purkinje cell bodies (Figs $12 \mathrm{a} \& \mathrm{~b}$ )

Immunohistochemical staining for GFAP in subgroup IIa rat cerebral cortex, showed glial proliferation based in the generalized increase of the immunoreactin with many processes around degenerated cells and around dilated vessels (Fig13a) .In subgroup IIb the GFAP immunoreaction was mildly increased in compared to other subgroups (Fig 13b ).
Marked GFAP immunoreaction intensity with multiple astrocyte reddish brown process was observed in subgroupIIc (Fig 13c).Notice the reactive gliosis of pial surface appeared in (Fig $13 \mathrm{c}$ inset). In protected group mild immunoreaction of astrocyte proliferation and process were detected (Fig $13 \mathrm{~d}$ )

Immunohistochemical staining showed that GFAP-positive astrocytes were more abundant and appeared larger in the three cerebellar cortical layers in subgroup IIa (Fig14 a). Mild immune reaction in subgroup IIb was noticed as compared to control subgroups (Fig.14 b). On the contrary, there was intense GFAP immune reaction in subgroup IIc with marked proliferation of astrocyte processes around abnormal degenerated Purkinje cells. (Fig14c).

In protected group, revealed mild immune reaction of GFAP astrocytes around normal looking Purkinje cells and granular cells. Radial band radiating in the molecular layer were also noticed (Fig15a 7b).

3. Morphometric and statistical analysis:

Mean area percent (area \%) of GFAP immunoreaction in astrocytes of all groups was measured in cerebral cortex as shown in (histogram 1) and in cerebellum in (histogram 2). Statistical analysis of the obtained data of area percent of GFAP immunoreaction showed significant increase in the treated subgroups IIa and IIc when compared with the control group. On the other hand, a non-significant increase of the immune reaction was obtained in subgroup IIb or in the protected group when compared with the control group.

Histogram 3 demonstrated the number of normal Purkinje cells counted in cerebellar cortex by morphometric study. There was a significant decrease of normal appearing Purkinje cells in subgroups IIa, more decrease in subgroup IIc compared to control group. While in subgroups IIb and group III the decrease of cells were not significantly detected.

Table (1): Superoxide dismutase (SOD) activity, catalase (CAT) activity and malondialdehyde (MDA) in cerebral and cerebellar cortices of control (Ia \&Ib), iron (IIa), silicon (IIb), iron and silicon (IIc) treated groups and omega-3 protected group (III) and comparison with control (Ia) and iron and silicon (IIc) groups

\begin{tabular}{|c|c|c|c|c|c|c|c|}
\hline $\begin{array}{l}\text { Cerebral } \\
\text { cortex }\end{array}$ & $\begin{array}{c}\text { Saline- } \\
\text { control } \\
\text { group (Ia) } \\
\mathbf{n = 5}\end{array}$ & $\begin{array}{c}\text { Omega -3 } \\
\text { control } \\
\text { group }(\mathrm{Ib}) \\
=5\end{array}$ & $\begin{array}{c}\text { iron treated } \\
\text { group (IIa) } \\
\mathbf{n = 1 0}\end{array}$ & $\begin{array}{c}\text { silicon } \\
\text { treated } \\
\text { Group (IIb) } \\
\mathbf{n = 1 0}\end{array}$ & $\begin{array}{c}\text { Iron and } \\
\text { silicon } \\
\text { Treated } \\
\text { group (IIc) } \\
\text { n=10 }\end{array}$ & $\begin{array}{c}\text { Protected } \\
\text { Group (III) } \\
\mathbf{n = 1 0}\end{array}$ & $\begin{array}{c}\text { ANOVA } \\
\text { P }\end{array}$ \\
\hline & mean \pm SD & mean \pm SD & mean \pm SD & mean \pm SD & mean \pm SD & mean \pm SD & mean \pm SD \\
\hline $\begin{array}{l}\text { SOD }(U / m g \\
\text { protein) }\end{array}$ & $9.89 \pm 1.40$ & $10.80 \pm 0.98 \bullet$ & $5.67 \pm 0.73 * \bullet$ & $7.56 \pm 0.80 * \bullet$ & $3.37 \pm 0.58 *$ & $8.00 \pm 0.66^{*} \bullet$ & $\begin{array}{l}5.01 \\
0.021 * \\
\end{array}$ \\
\hline $\begin{array}{l}\text { CAT (U/mg } \\
\text { protein) }\end{array}$ & $2.56 \pm 0.05$ & $2.70 \pm 0.030 \bullet$ & $1.43 \pm 0.09 * \bullet$ & $1.96 \pm 0.05 * \bullet$ & $1.14 \pm 0.07 *$ & $2.26 \pm 0.13 *_{\bullet}$ & $\begin{array}{l}4.69 \\
0.031 * \\
\end{array}$ \\
\hline $\begin{array}{l}\text { MDA (nmol } \\
\text { / gm tissue) }\end{array}$ & $232 \pm 9.40$ & $240 \pm 11.10^{\bullet}$ & $367 \pm 10.10^{*}$ & $300 \pm 9.74 *_{\bullet}$ & $388 \pm 9.60 *$ & $260 \pm 8.60 * \bullet$ & $\begin{array}{l}6.21 \\
0.011 * \\
\end{array}$ \\
\hline \multicolumn{8}{|l|}{ cerebellum } \\
\hline $\begin{array}{l}\text { SOD }(U / m g \\
\text { protein) }\end{array}$ & $6.96 \pm 0.77$ & $7.32 \pm 0.56 \bullet$ & $4.15 \pm 0.34 * \bullet$ & $5.08 \pm 0.64 * \bullet$ & $3.35 \pm 0.55 *$ & $5.82 \pm 0.33 *_{\bullet}$ & $\begin{array}{l}5.23 \\
0.019 *\end{array}$ \\
\hline $\begin{array}{l}\text { CAT }(U / m g \\
\text { protein) }\end{array}$ & $2.50 \pm 0.240$ & $2.48 \pm 0.34 \bullet$ & $1.54 \pm 0.11 *$ & $2.25 \pm 0.19 \bullet$ & $1.65 \pm 0.25 *$ & $2.08 \pm 0.11{ }^{*}$ & $\begin{array}{l}6.11 \\
0.013 *\end{array}$ \\
\hline $\begin{array}{l}\text { MDA (nmol } \\
\text { / gm tissue) }\end{array}$ & $204 \pm 10.40$ & $207 \pm 12.10^{\bullet}$ & $325 \pm 12.10 * \bullet$ & $289 \pm 8.74 * \bullet$ & $366 \pm 9.60 *$ & $220 \pm 11.20 \bullet$ & $\begin{array}{l}4.21 \\
0.041 * \\
\end{array}$ \\
\hline
\end{tabular}

Data are expressed as mean $\pm S D,\left(^{*}\right)$ indicates significant difference with control group, $(\bullet)$ indicates significant difference with iron and silicon treated group according to post hock test $(p<0.05)$. 
Table (2): The changes in the mean of GFAP intensity in cerebral and cerebellar cortices in the studied groups compared to control group (Ia)

\begin{tabular}{|l|l|l|}
\hline \multicolumn{1}{|c|}{ groups } & \multicolumn{1}{c|}{ Cerebral cortex } & \multicolumn{1}{c|}{ Cerebellar cortex } \\
\hline \multicolumn{1}{|c|}{} & Mean \pm SD & Mean \pm SD \\
\hline Saline-control group (Ia) & $15.96 \pm 3.11$ & $16.21 \pm 2.66$ \\
\hline Omega control group (Ib) & $16.3 \pm 4.8$ & $15.97 \pm 2.98$ \\
\hline iron treated group (IIa) & $23.89 \pm 5.16^{*}$ & $21.92 \pm 5.18^{*}$ \\
\hline silicon treated Group (IIb) & $19.45 \pm 5.12$ & $18.57 \pm 5.23$ \\
\hline Iron and silicon Treated group (IIc) & $27.12 \pm 5.98^{*}$ & $23.79 \pm 5.29^{*}$ \\
\hline Protected Group (III) & $16.5 \pm 3.11$ & $17.25 \pm 3.71$ \\
\hline ANOVA & 7.98 & 6.11 \\
P & $0.011^{*}$ & $0.026^{*}$ \\
\hline
\end{tabular}

Data are expressed as mean $\pm S D,\left(^{*}\right)$ indicates significant difference with control group (Ia) according to post hock test $(p<0.05)$.

Table (3): The changes in the mean number of normal Purkinje cells in cerebellar cortex of the studied groups compared to control group (Ia)

\begin{tabular}{|l|l|}
\hline \multicolumn{1}{|c|}{ group } & \multicolumn{1}{c|}{ Mean \pm SD } \\
\hline Saline-control group (Ia) & $22.3 \pm 1.69$ \\
\hline Omega control group (Ib) & $23.1 \pm 2.33$ \\
\hline Iron treated group (IIa & $15.8 \pm 1.27 *$ \\
\hline Silicon treated Group (IIb) & $18.9 \pm 1.43$ \\
\hline Iron and silicon treated group (IIc) & $11.5 \pm 1.21 *$ \\
\hline Protected Group (III) & $21.2 \pm 1.73$ \\
\hline ANOVA & 5.07 \\
P & $0.038^{*}$ \\
\hline
\end{tabular}

Data are expressed as mean $\pm S D,\left(^{*}\right)$ indicates significant difference with control group (Ia) according to post hock test $(p<0.05)$.

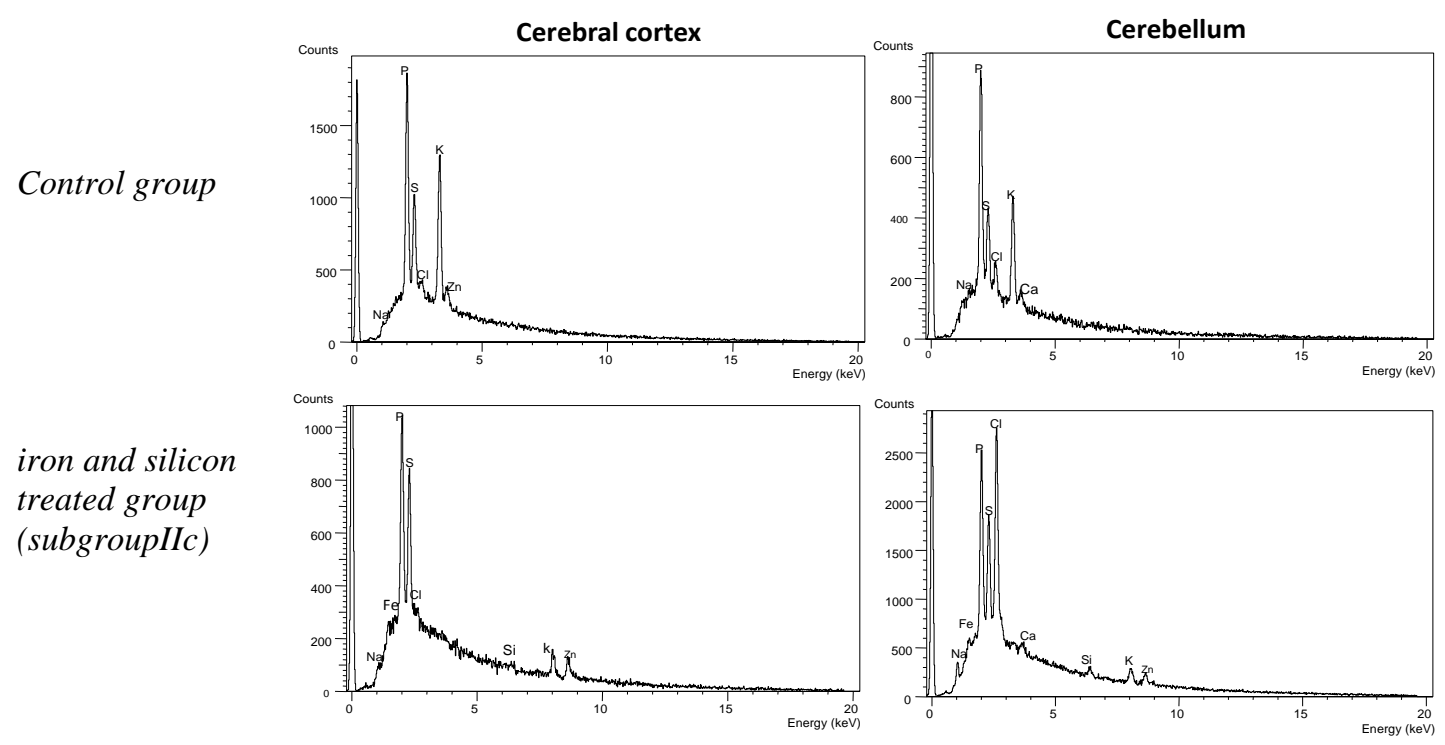

Figure (1): X-ray intensity at randomly selected point of cerebral cortex and cerebellum sections of the control rats and iron and silicon treated rats (subgroup IIc). 


\section{Cerebral cortex \\ SOD}
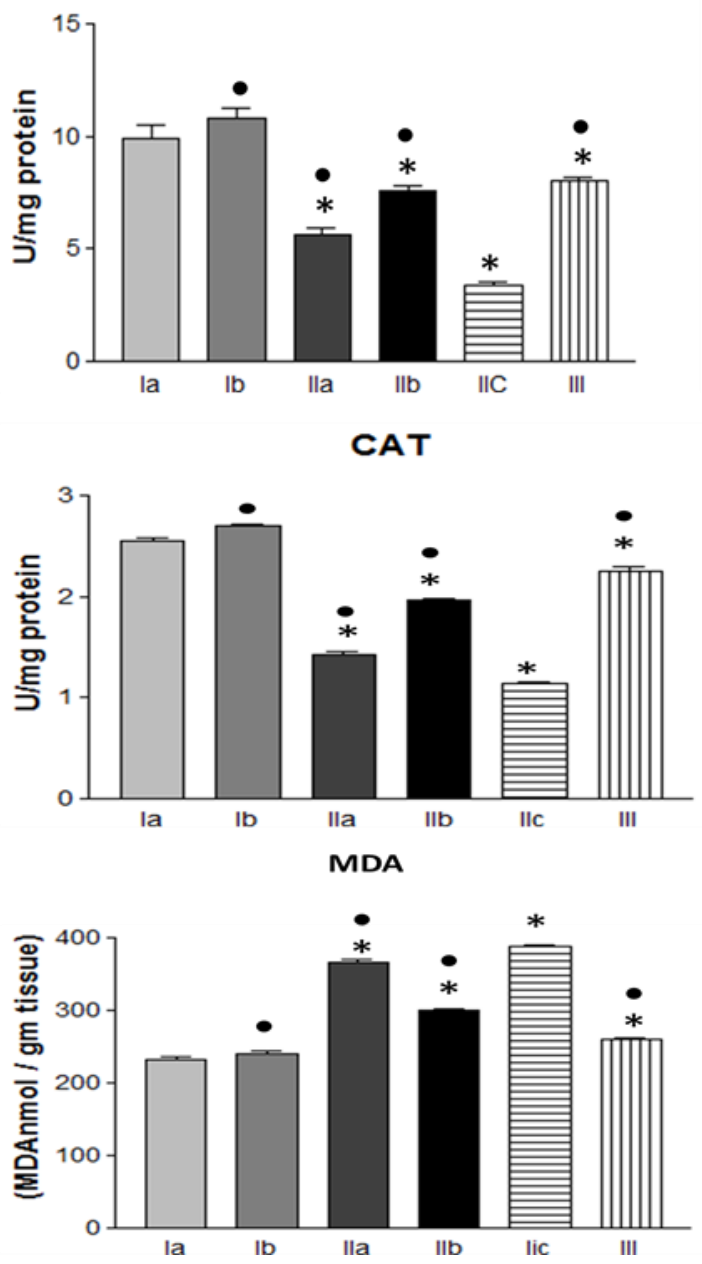

cerebellum

SOD
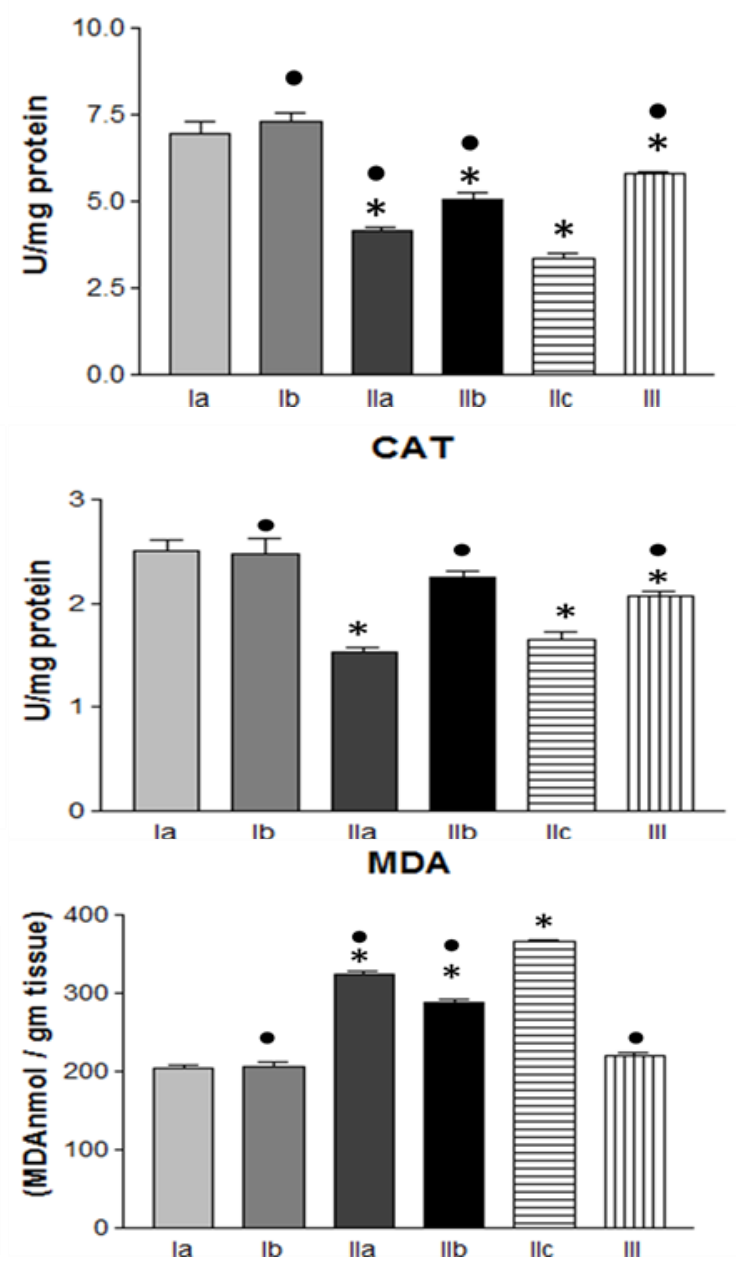

Figure (2): Superoxide dismutase (SOD) activity, catalase (CAT) activity and malondialdehyde (MDA) in cerebral and cerebellar cortices of control (Ia \&Ib), iron (IIa), silicon (IIb), iron and silicon (IIc) treated groups and omega-3 protected group (III) and comparison with control (Ia) and iron and silicon (IIc)groups. (*) indicates significant difference with control group and $(\bullet)$ indicates significant difference with iron and silicon treated group according to post hock test $(p<0.05)$.
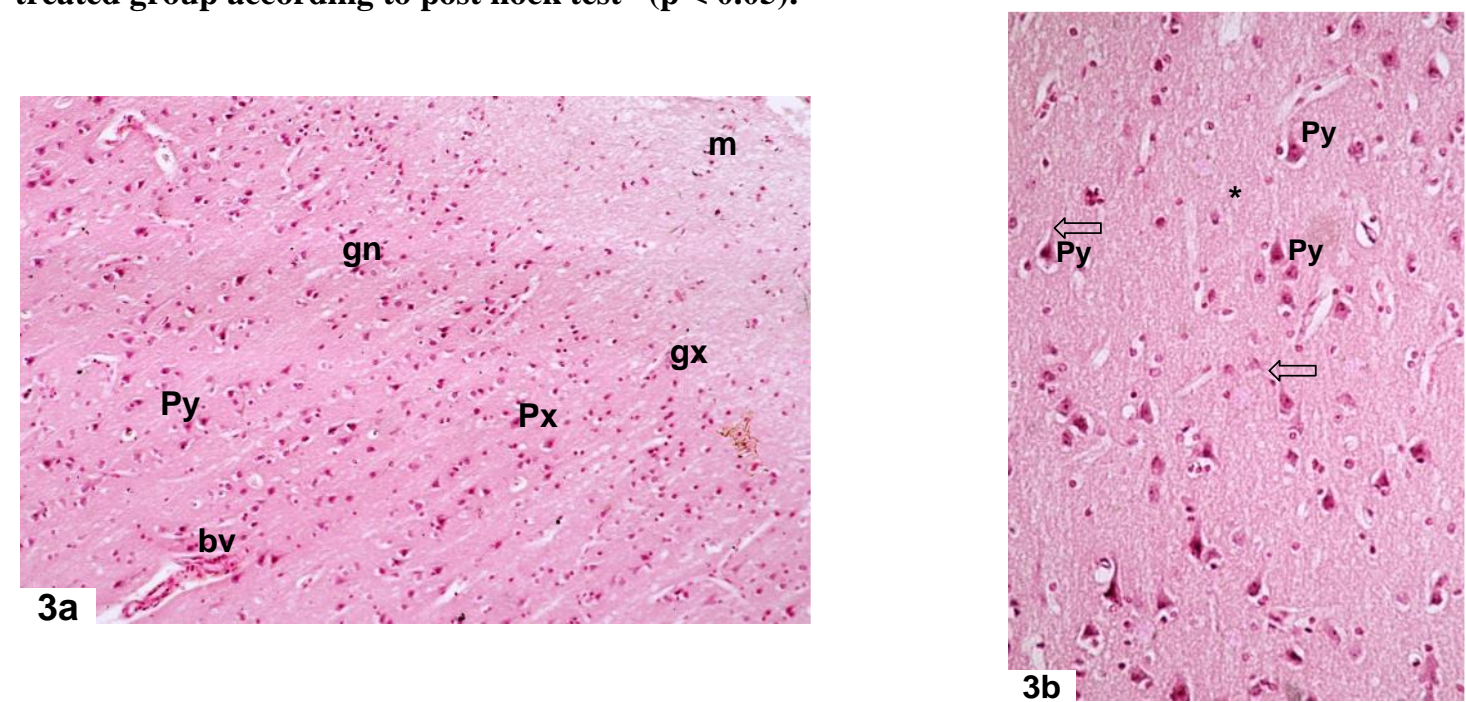

Fig. 3(a\&b): Light micrographs of control rat cerebral cortex showing, (a): Well defined layers; the molecular layer (m), external granular layer (gx), external pyramidal layer (px), internal granular layer (gn), inner pyramidal cells(py) and cerebral blood vessels (bv). (b): Higher magnification of the motor area revealing the triangular bodies of pyramidal $(P y)$ cell with vesicular nuclei and apical dendrites directed upwards (arrow) surrounded by pale acidophilic neuropil (*). (H\&E stain Mic Mag.x100 \& 400). 

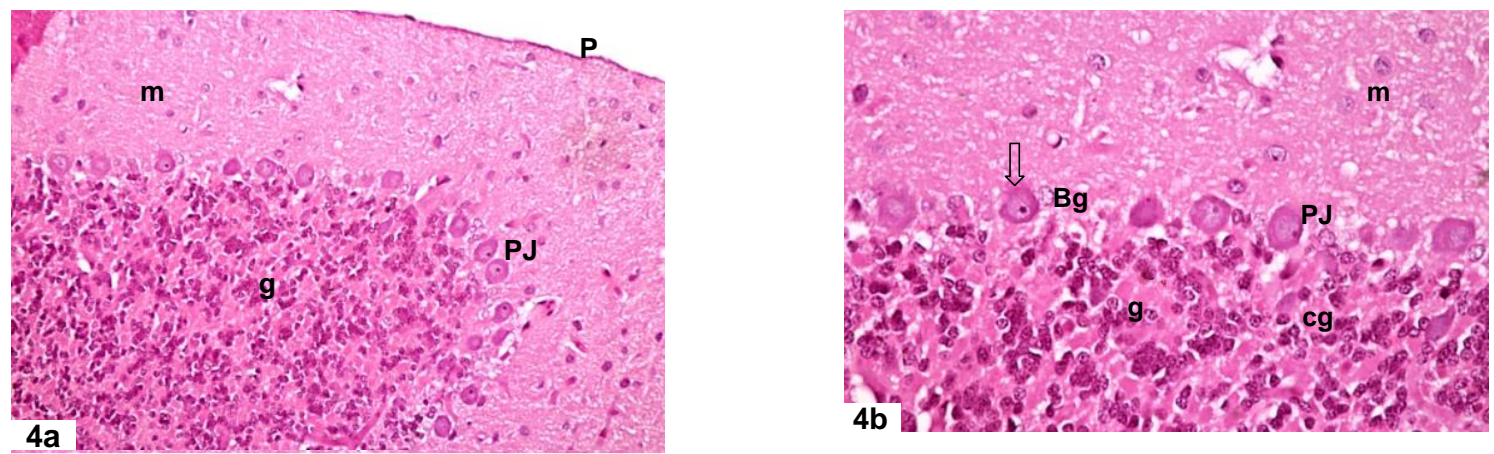

Fig. 4 (a\&b): Light micrographs of control rat cerebellar cortex showing, (a) low power view of cerebellar cortex covered by pia matter ( $p)$ with arranged molecular layer(m), Purkinje cell layer(Pj) and granular layer(g).(b): Higher magnification of the Purkinje cell layer (Pj)appearing as a single layer of pear shaped cell with apical dendrite(arrow) arborizing in the molecular layer(m). Bergmann cell nuclei are seen around Purkinje cell bodies (Bg). The granular layer shows closely aggregated granule cell nuclei (g) separated by cerebellar glomeruli (cg).(H\&E stain Mic Mag a\&b x 100 \&400).
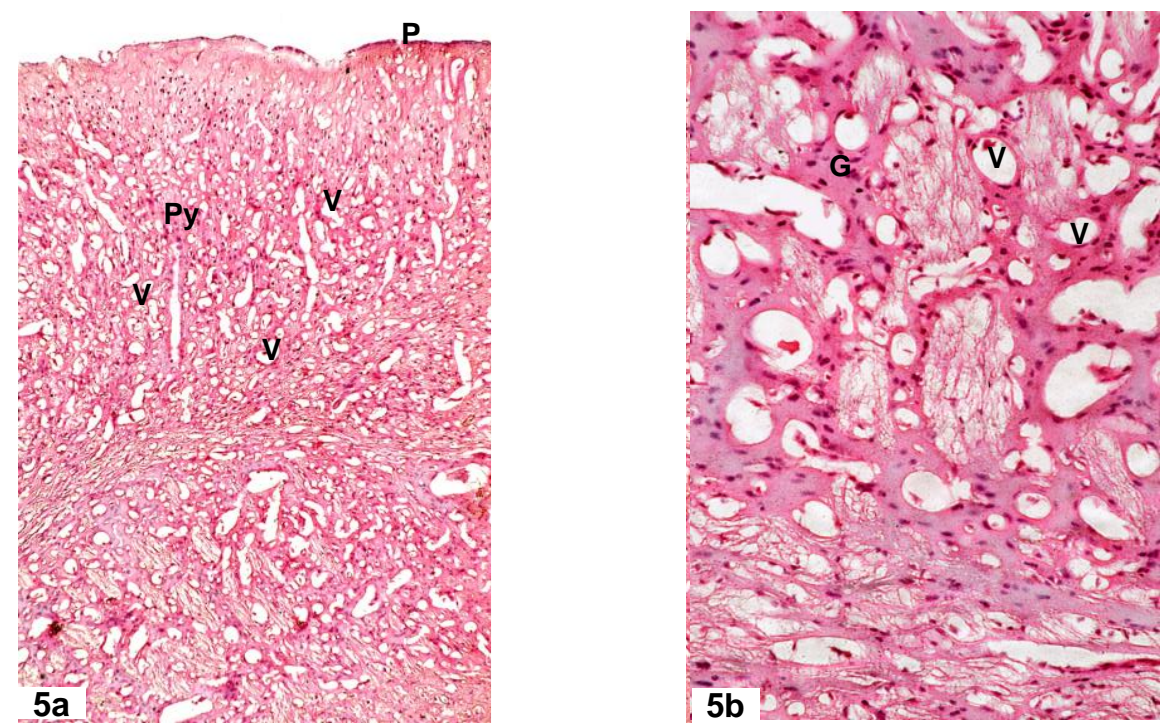

Fig 5.(a\&b): Light micrographs of cerebral cortex of treated subgroup IIa showing ill-defined cortical layer with marked tissue vacoulation (V), degenerated pyramidal cells (Py) exhibiting dense small nucleus and dark acidophilic cytoplasm in (5a). Granular cells appear degenerated $(G)$ in $(5 b)$. Pial surface $(P)(H \& E$ stain Mic Mag a\&b x $100 \& 400)$.
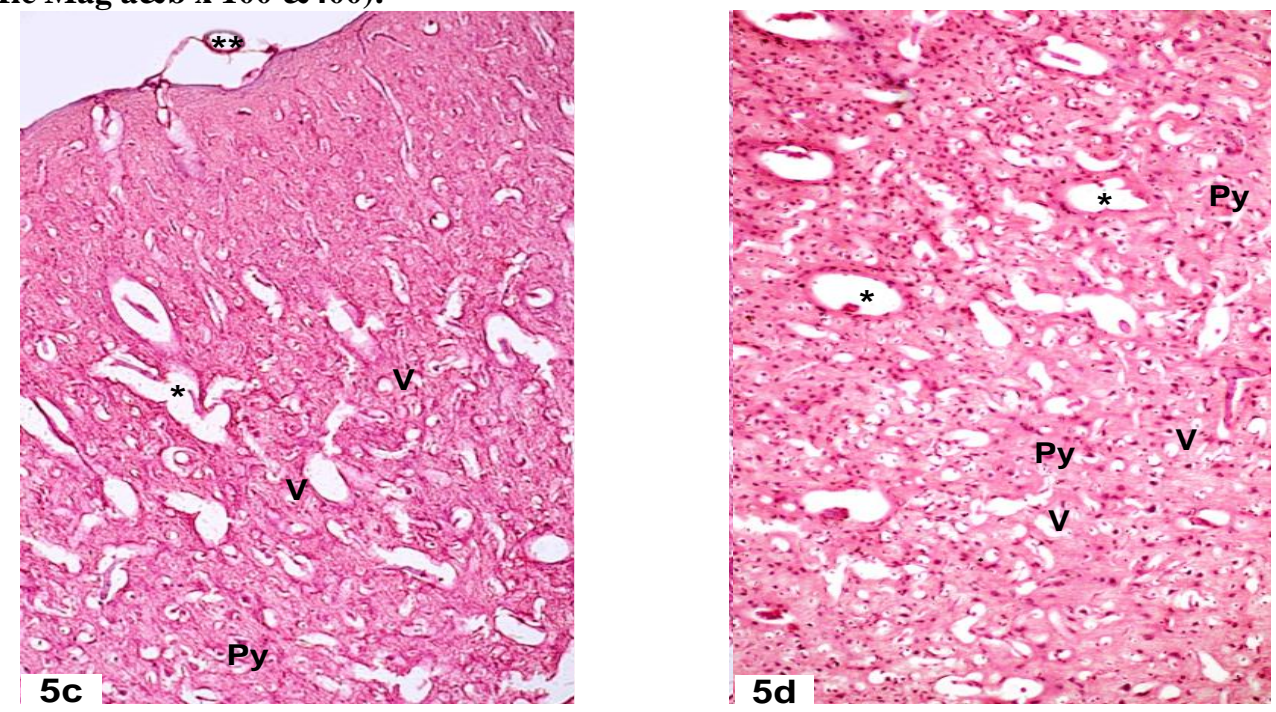

5. (c\&d): Light micrographs of subgroup IIb rats showing disorganized cerebral cortical layers with multiple vacoulation $(V)$, degenerated pyramidal cells surrounded by a halo (Py).Dilated blood vessels; $(*)$ pial blood vessel; (**).(H\&E stain Mic Mag c\&d x 200 \&400). 

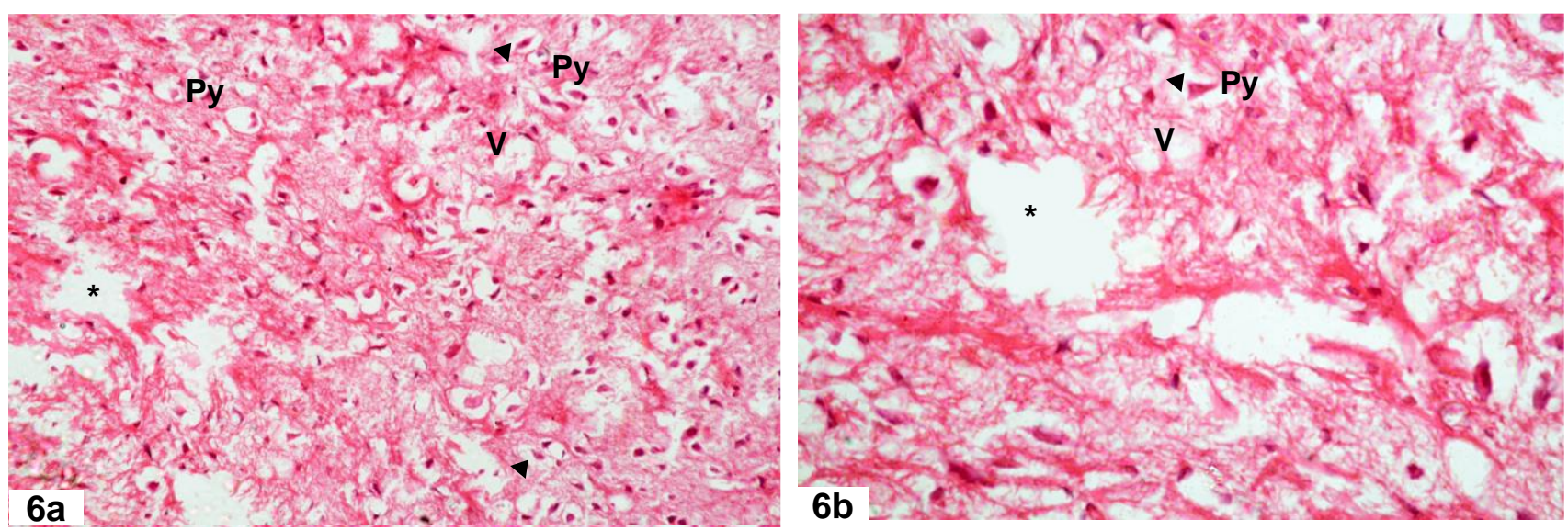

Fig. 6(a\&b): Light micrographs of cerebral cortex of combined treated subgroup IIc revealing ill-defined layers with vacoulation (V), degenerated pyramidal cells (Py) surrounded by a halo, degeneration of neuropil (arrow head) with areas of dense neuropil in (6b) and focal loss of brain tissue (*).(H\&E stain Mic Mag. a\&b x 200 \&400).
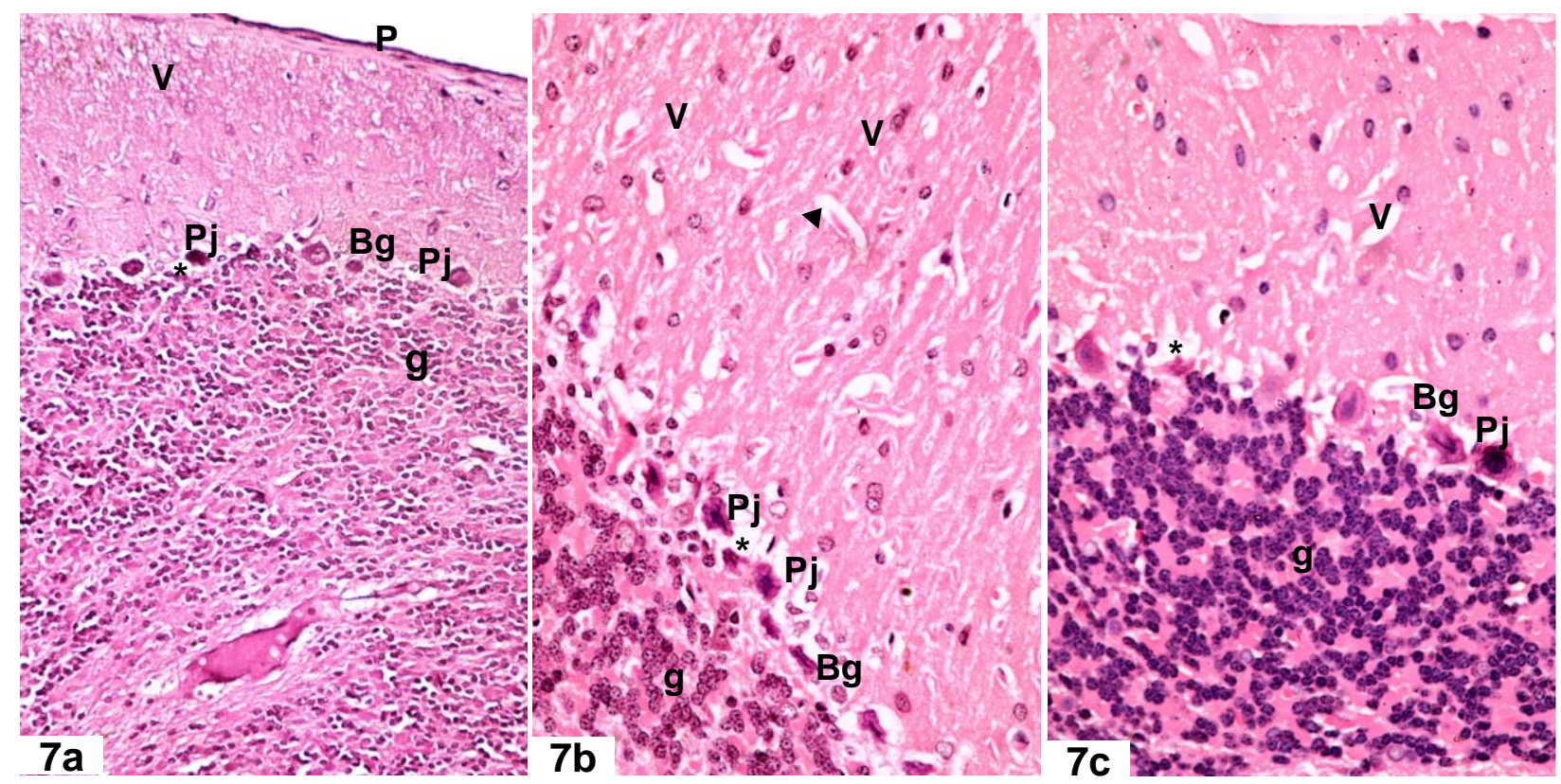

Fig. 7(a,b\&c): Light micrographs of cerebellar cortex of treated group, revealed

(a\&b): rats of subgroup IIa depicting preservation of the cerebellar cortical layers, marked reduction of normal Purkinje cell (PJ) most of them appear with pyknotic nuclei and interstitial separation(*) between the cells especially in iron treated subgroup IIa. Some vacoulation(v) and dilated vessels $(\wedge)$ in the molecular layer Notice the thickened pia layer(P) in fig. 7 a.

C: cerebellar cortex of subgroup IIb showing some degenerated Purkinje cells (PJ) with dense nuclei while others are looking normal.

Bergmann cells $(\mathrm{Bg})$ in all figures, appears with vacuolated cytoplasm and some exhibiting dense nuclei. (H\&E stain Mic Mag. a\&b x100 \&200, c x200). 


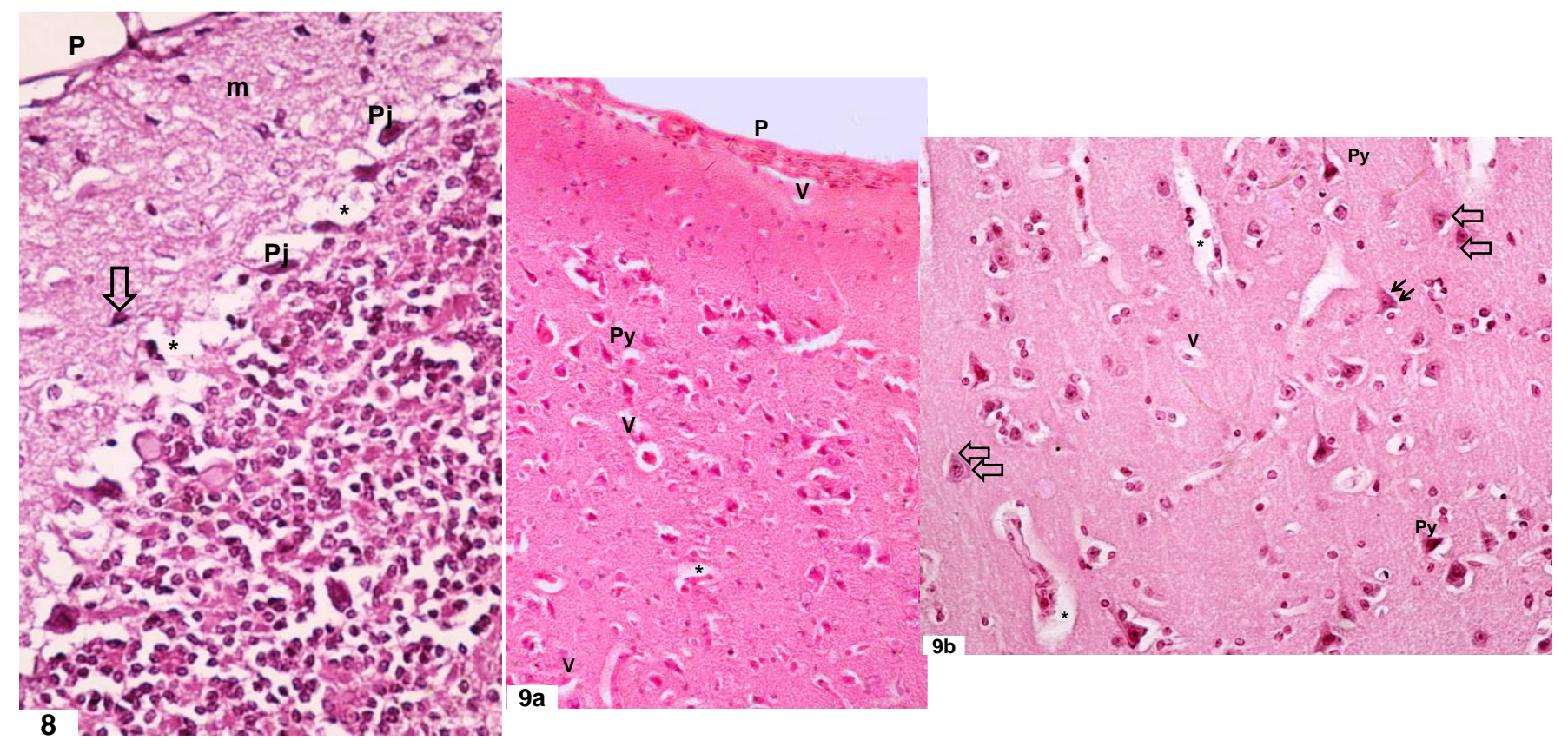

Fig. 8: Light micrograph of subgroup IIc rat cerebellar cortex showing, loosening of the molecular layer (m), loss of neurons in Purkinje cell layer leaving remnants of degenerated cells $(\mathbf{P j})$. Several pyknotic nuclei of degenerated cells (arrow) are revealed in the molecular and granular layers. Areas of wide interstitial separation are seen among the Purkinje neuron cell bodies (*). Pia matter (p).(H\&E stain Mic Mag x200).

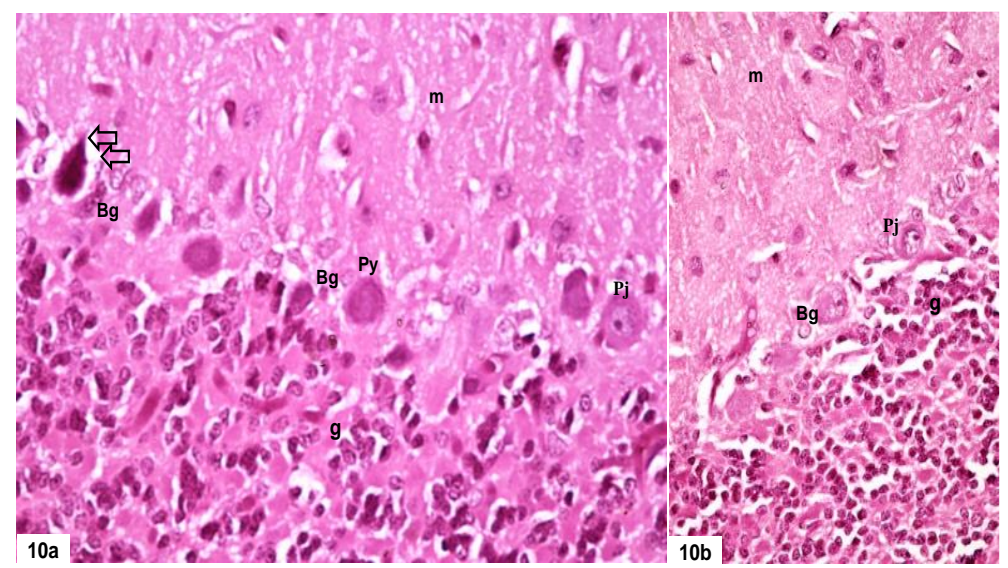

Fig. 10(a\&b): Light micrographs of protected group rat cerebellar cortex revealing normal looking cerebellar cortical tissue. Purkinje cells (PJ) appears with vesicular nuclei and basophilic cytoplasm while others are still degenerated with dense nucleus and dark acidophilic cytoplasm (double arrow) surrounded by wide interstitial space. Restoration of surrounded Bergmann cells (Bg). Molecular (m) ;granular layer(g).(H\&E stain Mic Mag. a\&bx 400).
Fig. 9( $\mathbf{a \& b}$ ): Light micrographs of cerebral cortex of protected group showing focal areas of vacoulations $(V)$ of the cortical tissue and dilated vessels (*). Some Pyramidal cells $(P y)$ are dense while others are looking normal (double arrow). Notice the thickened pial layer (p) in (9a) $(H \& E$ stain Mic Mag 400).

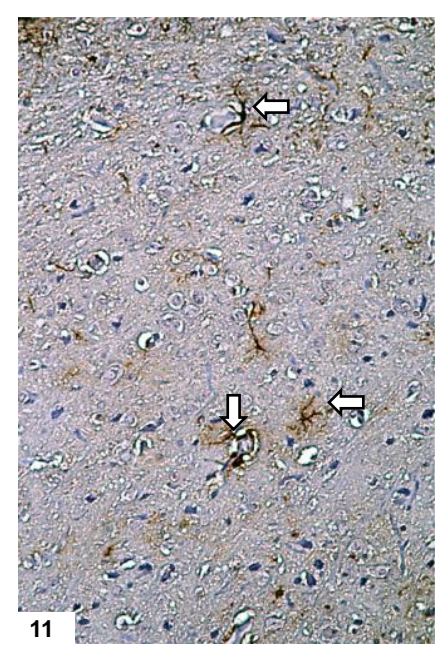

Fig. 11: Photomicrograph of control rat cerebrum immunohistochemically stained with monoclonal glial fibrillary acidic protein antibody (GFAP) demonstrating normal immunoreaction in the form of scattered immunoreactivity of stellate astrocytes. The delicate short processes of the astrocytes are seen embracing the blood capillaries (arrow).(Mic Mag. X400). 

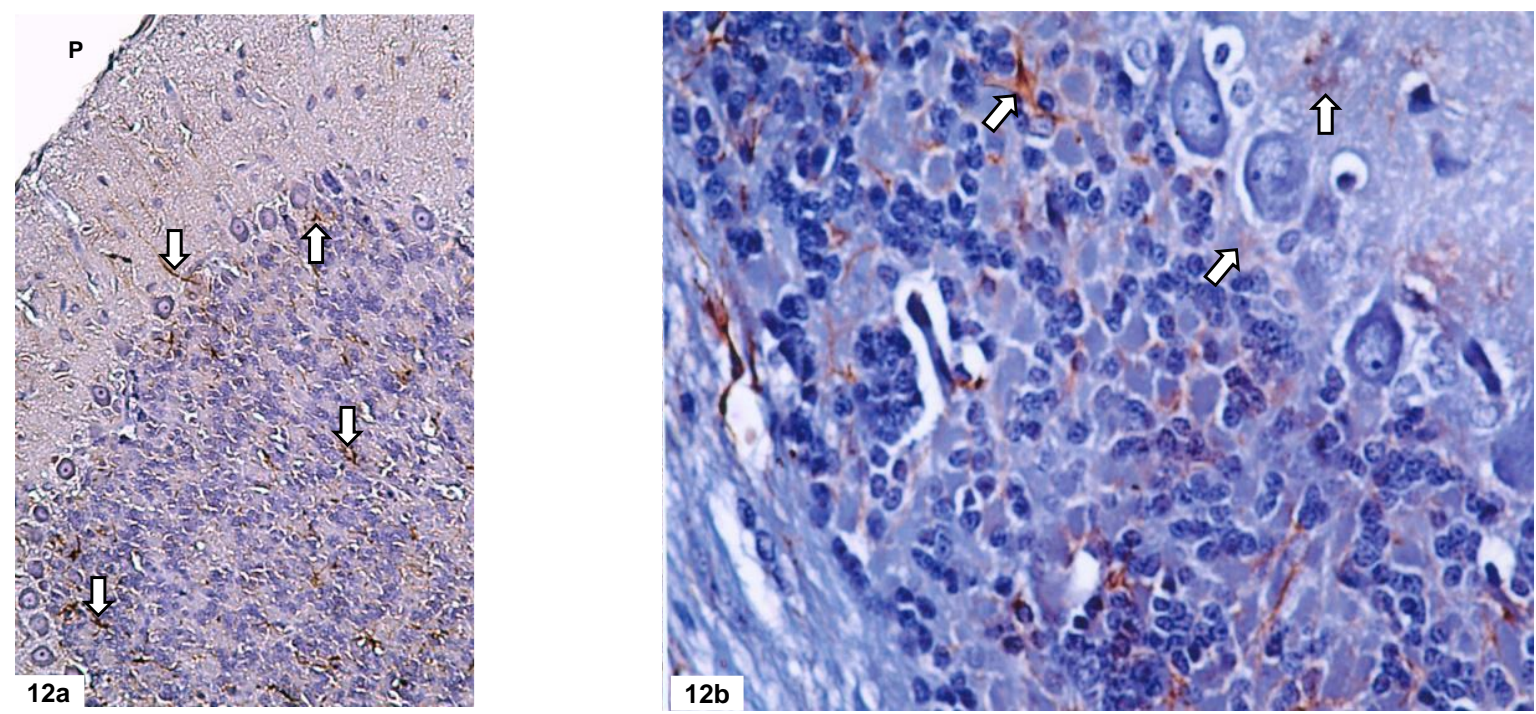

Fig. 12(a\& b): Photomicrographs of control rat cerebellar cortex immunohistochemically stained with monoclonal glial fibrillary acidic protein antibody (GFAP) demonstrating normal immunoreaction in the form of scattered immunoreactivity of stellate astrocytes(arrow) in the molecular layer especially in the outer zone, around Purkinje cell bodies and granular layer. (Mic Mag.12 aX100 \&12 b X400).
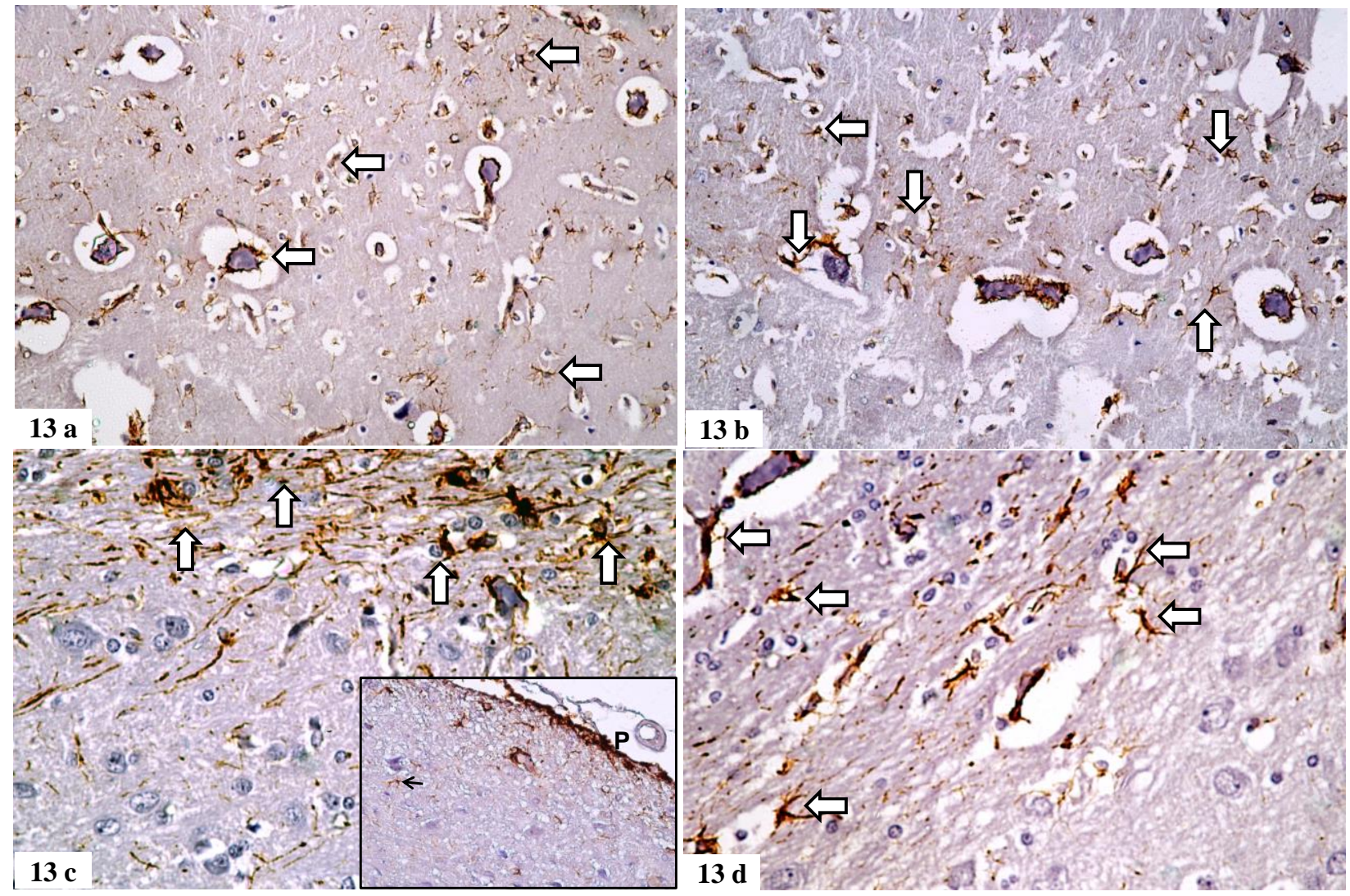

Fig. 13(a,b,c \&d): Photomicrographs of experimental rat groups, cerebrum stained with body (GFAP) demonstrating GFAP-positive staining of the cytoplasm and processes of astrocytes(arrow). They were apparently increased in number and appeared larger with thick processes especially in subgroup IIa (13 a), compared to subgroup IIb as seen in (13 b). In fig. 13c, GFAP-positive astrocytes in subgroup IIc were more abundant intense reaction and appeared larger especially in the white matter and pial surface (P) (13 $\mathrm{c}$ inset). In (13d) GFAP of protected group demonstrating decrease immunoreaction in the form of scattered stellate astrocytes in the multiform layer. The delicate short processes of the astrocytes are seen embracing some of the blood capillaries (arrow). (Mic.Mag X200). 


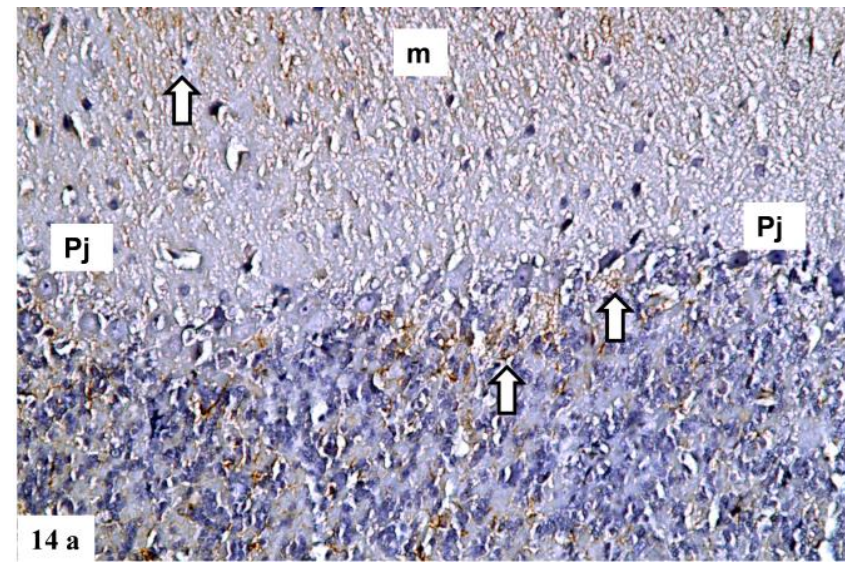

Fig. 14(a,b\&c): Photomicrographs of rats subgroup

IIa \&IIb cerebellar cortex stained with (GFAP) 14 a: showing intense positive immunoreaction in the cytoplasm and processes(arrow) of many astrocytes around the degenerated Purkinje cell bodies(Pj). ( Fig 14 b GFAP) subgroup IIb demonstrating mild increase intensity reaction(arrow) . subgroupII c (GFAP) showing marked increase in the intensity of the immunoreaction in all layers and around degenerated Purkinje(Pj) and granular cells (14 c). (Mic. Mag X200).
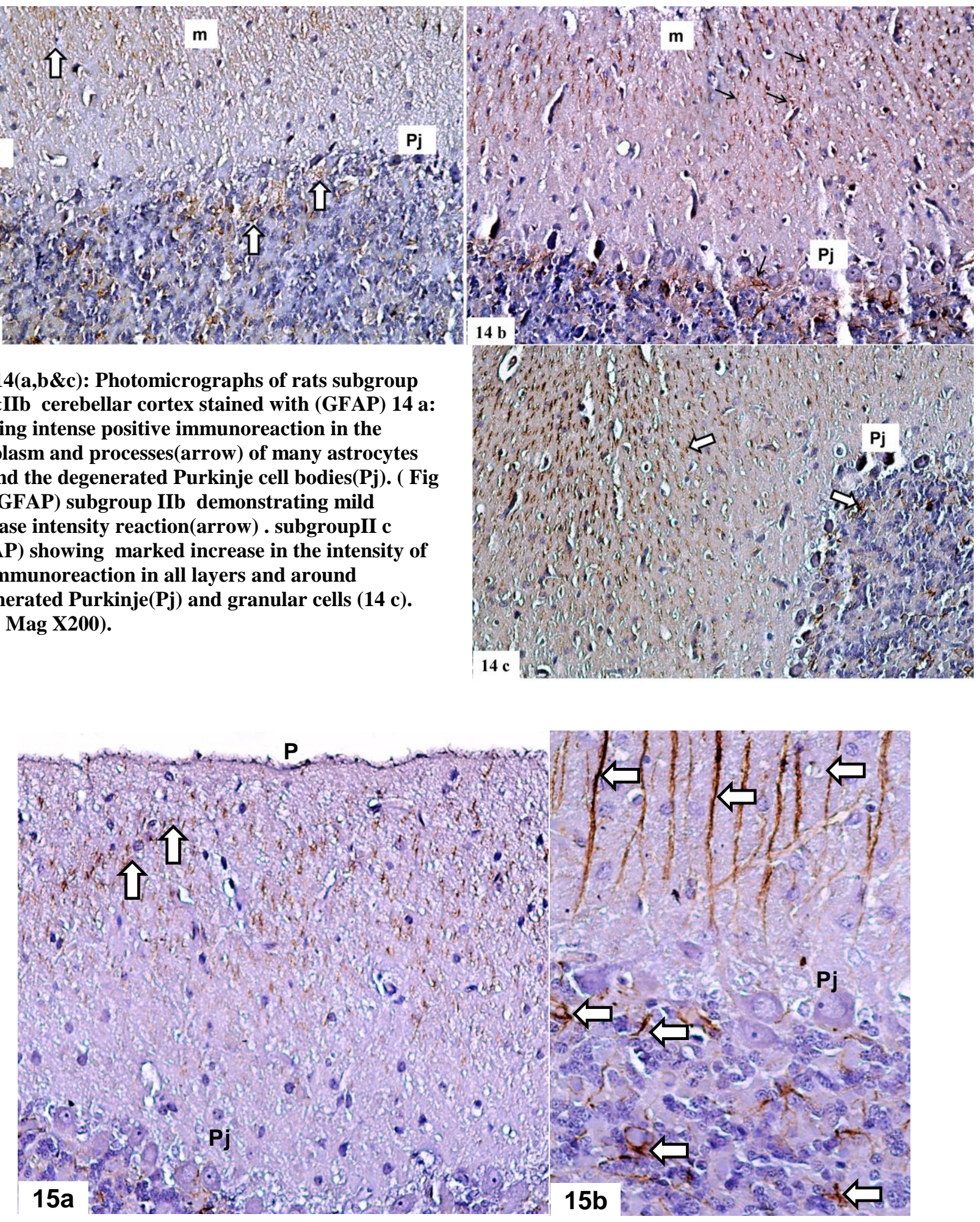

Fig. 15(a\&b): Photomicrograph of rat cerebellar cortex of protected group showed decreased GFAP intensity around normal Purkinje cells ( $\mathrm{Pj}$ )with radial bands extending in the molecular layer(arrow) as shown in (15 b). Pial surface (P). (Mic. Mag X200). 


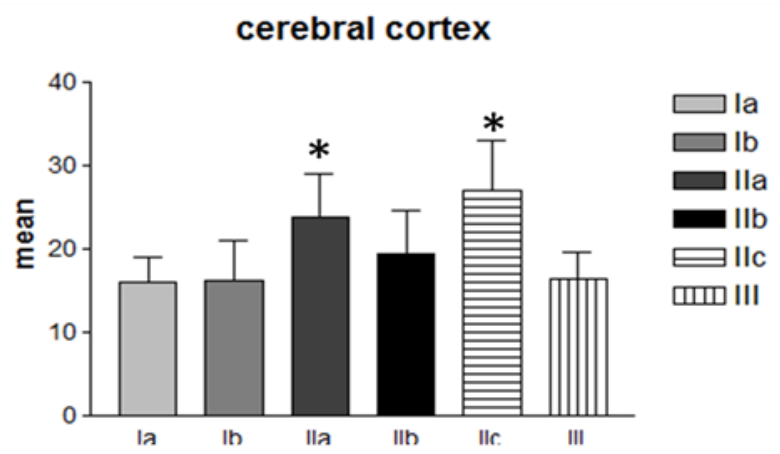

Histogram (1): showing the changes in the mean GFAP intensity in cerebral cortex of the studied groups (*) indicates significant difference wi

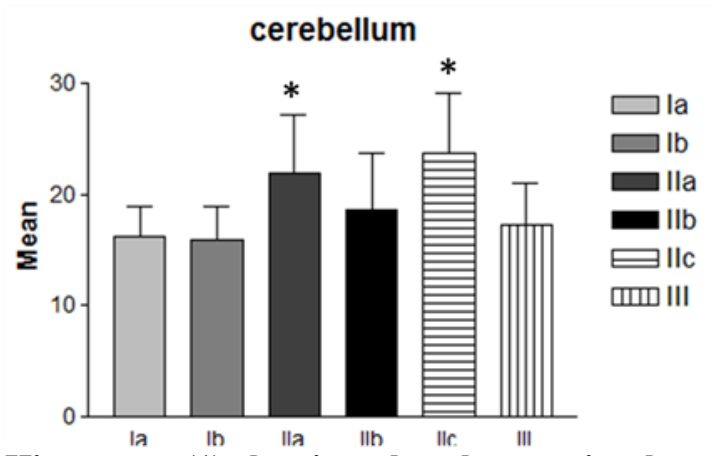

Histogram (1):showing the changes in the mean GFAP intensity in cerebellum of the studied groups

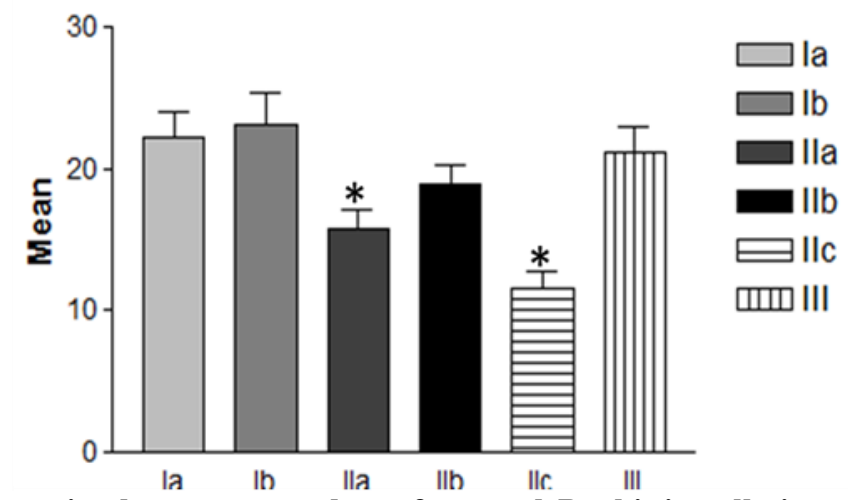

Histogram (3): The changes in the mean number of normal Purkinje cells in cerebellar cortex of the studied groups compared to control group (Ia). (*) indicates significant difference with control group (Ia) according to post hock test $(p<0.05)$.

\section{Discussion}

Prolonged exposure to cement dust has been considered as one of the environmental pollutants and suggested to cause high incidence of various clinical conditions, including respiratory and non-respiratory systems involvement (Meo, 2004; Manjula et al., 2013).

Lack of information about the systemic effects of exposure to the cement is surprising since many researches described the respiratory effects. Currently, the present work aimed to assess the effect of cement on cerebral cortex and cerebellum. Content of Portland cement is a mixture of different elements that include iron and silicon that were studied in the present work.

The used doses in the present study provided as threshold limit value for working day in Egyptian labour law for adult workers, such dose was modified to fit experimental animal according to Paget and Barnes (Abd El-Rahman et al., 2011).

The dosage was given orally to mimic the route of human exposure that include alimentary tract that in turn distributed to the different tissues.

Several imaging techniques have been used to study the brain architecture to obtain data for chemical elements present in. Energy Dispersive X-ray Spectrometry (EDX) identifies the elemental composition of materials imaged in a Scanning Electron Microscope. EDX is able to perform rapid, simultaneous multi-element analysis without any special sample preparation (Braidy 2014).
Therefore, EDX was used in the present study. Control samples (cerebral and cerebellar cortices) of non-treated control rats showed no peaks for iron or silicon.

Similar results were obtained by Takahashi et al. (2000). They concluded that the measured elements of non treated rat brain were $\mathrm{Na}, \mathrm{P}, \mathrm{S}, \mathrm{Cl}, \mathrm{K}$ and $\mathrm{Ca}$.

Oral administration of both iron and silicon for eight weeks induced a detected increase of these two elements content in cerebral and cerebellar cortices showing their peaks in EDX spectra.

In the present work, the histological findings go hand by hand with the biochemical results. The cerebral cortex of treated animals that received iron (subgroup IIa) showed various degrees of degeneration with ill-defined layers, multiple vacuolation and spongification of cortical tissue neuropil. The pyramidal cells were degenerated with pyknotic nuclei.

The cerebellum of subgroup IIa showed lesser affection than the cerebral cortex with noticed reduction in the number of normal Purkinje cells which appeared with dark basophilic cytoplasm, small dark nucleus and wide perineuronal spaces, also thickened glial surface were observed. The granular layer showed multiple dense nuclei. These results were consistent with Chaudhary et al. (2014) study who reported similar cerebellar tissue alteration after aluminum exposure. 
These histological changes might be explained in the light of the present biochemical results. A significant increase in oxidative stress was found in iron- treated rats as reflected by significant decrease in SOD and CAT activity. Furthermore, a significant increase in MDA was observed as well.

Meguro et al. (2007) stated that iron $(\mathrm{Fe})$ is essential for the proper functioning of many cellular processes. Due to its capability to catalyze oxidationreduction reactions, iron serves as an active site in molecules with critical biological functions. However, this also requires a strict regulation to prevent uncontrolled spreading of catalytically active iron and its potential neurotoxicity.

Ferrous ion participates in the Fenton reaction decomposing $\mathrm{H}_{2} \mathrm{O}_{2}$ with the formation of hydroxyl radical $(\mathrm{OH} \bullet)$ which is recognised as the most reactive and destructive intermediate. It also causes chaininitiation reaction of lipid peroxidation that leads to a vicious cycle of cellular damage (Gutteridge, 1984; Halliwell, 1992).

On the other hand, brain is considered as a highly vulnerable organ to iron-induced oxidative stress because of a relative lack of antioxidant enzymes and abundance of oxidizable substrates like polyunsaturated fatty acids, catecholamines etc. (Halliwell and Gutteridge, 1985 ). Moreover, neurons are enriched in mitochondria and have a high aerobic metabolism (Halliwell 2006).

In the present study, subgroup IIb showed cerebral and cerebellar histological alteration affection. The cerebral cortex appeared with multiple tissue vacoulation, loss of cortical demarcation areas and degenerated pyramidal and granular cells.

In cerebellar cortex, some Purkinje cells were degenerated which was confirmed by morphometric \& statistical studies of Purkinje cell count.

Significant increase in oxidative stress has been also found in silicon treated rats. It was demonstrated as a significant decrease in SOD and CAT activity with a significant increase in MDA as well. Yet, CAT activity in subgroup (IIb) of cerebellum showed non-significant decrease compared with control group. It may explain the lesser affection of cerebellum than cerebral cortex.

In accordance with the current study, Yang et al (2009) concluded oxidative stress as a common mechanism for cell damage induced by silicon. A significant GSH depletion and ROS generation, in turn; the accumulation of ROS depleted and resisted the defensive effects of cellular antioxidant enzymes were demonstrated. Consequently, redundant free radicals would interact with biomolecules including proteins, enzymes, membrane lipids and even DNA which could be oxidized, modified, destructured and ultimately dysfunctioned.

In agreement with current observations, Wu et al study (2011) concluded that the exposure to silicate nano particles $\mathrm{SiO}(2)-\mathrm{NPs}$ decreased cell viability, triggered oxidative stress, disturbed cell cycle, induced apoptosis. In addition, $\mathrm{SiO}(2)-\mathrm{NPs}$ appeared to induce depleted dopamine and the down-regulation of tyrosine hydroxylase protein. This was the main contribution, which has a negative impact on dopaminergic neurons as well as a potential risk for neurodegenerative diseases.

In contrast to the present finding, Abd ElRahmana et al. (2011) stated that, prolonged administration of silicon caused a non-significant change in all the tested brain areas of the adult mice in different durations. They also concluded that it may indicate that silicon could not be hazardous solely. Yet, this study based on the effect of silicon on ion contents of the brain tissues and neither histological study nor oxidative profile was performed in their study.

Regarding rats treated with combined iron and silicon (subgroup IIc), the results of the present work clearly demonstrated that co-administration of both elements, as in cement mixture, induced more prominent and more toxic effects than the effect of each element. It appeared in the form of massive destruction of cortical tissue and more evident affection of the cerebellum. Moreover, few Purkinje cells were hardly detected. Such observations was supported by the present biochemical results, that revealed significant decrease of SOD and CAT associated with significant increase of MDA when compared with either treated subgroups (subgroup IIa or IIb). These results might be explained as additive oxidative stress that augments the histological alterations of the brain tissues.

These results was also confirmed by immunohistochemical study that showed GFAPpositive astrocytes significantly increased in the cerebral and cerebellar cortical layers in subgroups IIa compared to control group. While, in subgroup IIc there was more intense GFAP immunoreaction with marked proliferation of astrocytic processes. The striking surface reactive gliosis was obsorved in all treated subgroups.

Astrocytes are considered as an important indicator of brain injuries as it reacts rapidly to various neurodegenerative insults leading to vigorous astrogliosis. These cells play crucial physiological roles in brain functions through the release of several neurotrophic factors as a primary event in the maintenance of CNS homeostasis. However, it is believed that rapid and severe activation initiates an inflammatory response that leads to neuronal death and brain injury. (Pekny and Nilsson, 2005)

In response to various CNS injuries, astrocytes become activated and this process is called 'reactive gliosis'. This reaction has specific structural and functional characteristics with vigorous reaction as a main process. The signs of such reaction include increased number of glial cells, hypertrophy of astrocytes, and accumulation of cytoplasmic glial fibrillary proteins (Ridet et al., 1997; Kálmán, 2004).

After prolonged activation, astrocytes secrete various neurotoxic substances and express an enhanced level of GFAP, which is considered a marker protein for astrogliosis. However, the mechanism by which astroglial expression of GFAP is increased in neurodegenerative CNS remains unclear. Brahmachari et al.,(2006); and Murphy, (2000), reported that nitric 
oxide is instrumental in inducing the expression of GFAP in astrocytes.

Regarding purkinje cells in cerebellar cortex sections, a reduction in the number of normal cells was noticed in subgroup IIa and few normal Purkinje cells were hardly detected in group IIc.

Moreover, the changes in the cerebellar granular layer were thought to be secondary to changes in the Purkinje cells. As the degenerated Purkinje cells failed to establish contact with the granule cells, this led to lack of normal synchronism between them that might minimize their regulatory role. This idea was supported by earlier postulations that several environmental factors might be able to affect cerebellar interconnection (Zeenat and Zaidi, 2010; Chaudhary et al., 2014).

The present work, therefore, was undertaken to elucidate the potential contribution of Omega-3 polyunsaturated fatty acids (PUFA) as a neuroprotective agent against combined iron and silicon-induced toxicity.

Omega-3 polyunsaturated fatty acids (PUFA), are recognised as; Docosahexaenoic acid (DHA) which is the most common $n-3$ PUFA within phospholipids of brain cell membranes and eicosapentaenoic acid (EPA) that is usually found in very limited amounts in the central nervous system (Salem et al., 2001).

Brain is highly enriched in long chain polyunsaturated fatty acids (PUFAs) particularly (DHA) which plays an important role in brain structural and biological functions. DHA has wellcharacterized effects on inflammation and oxidative stress and may have neuroprotective effects in a number of neurodegenerative conditions including Alzheimer disease. (Yavin et al., 2002).

In the current work, microscopic examination of the protected group showed marked areas of cellular regeneration, tissue improvement and preservation in both cerebrum and cerebellum, compared to treated subgroups with still focal areas of incomplete recovery.

Moreover, the present results showed that omega-3 significantly recovers endogenous antioxidants; CAT and SOD which protect neurons against ROS.

Omega-3 is recognized as a physiologicallyessential nutrient in the brain. Omega-3 possesses certain antioxidative and neuroprotective properties. Several mechanisms have been proposed to explain omega-3 action as a cellular antioxidant. These mechanisms include; regulation of the level of reactive oxygen species or activation of cellular antioxidant enzymes (Kawakita et al., 2006).

Rifaai et al. (2011) stated also that Omega-3 can influence cell function through multiple mechanisms where DHA can be esterified into phospholipids of the plasma membrane bilayer significantly altering many basic membrane properties, including fluidity, flexibility and permeability.

Moreover, mechanism of action of omega-3 in the nervous system includes its modulator effects on the activity of ion channels that thought to underlie its role in supporting electrical signalling and brain functioning (Kawakita et al., 2006).
Immunohistomical study confirmed the results. GFAP intensity in protected group revealed marked reduction due to ameliorating effect of omega3 and nearly normal number of Purkinje cells can be detected

Therefore, the beneficial protective effect of omega-3 appeared to be mediated via antioxidant effect that may be coupled with other mechanisms. It renders omega-3 is a hopeful neuroprotective agent in toxic exposure to cement components (iron and silicon).

\section{Conclusion}

The present work revealed the hazardous effect of cement component (iron and silicon) on cerebral cortex and cerebellum. Therefore, workers and health officials should work together to adopt technical preventive measures .Further studies are needed to magnitude the problem on health effects either respiratory or nonrespiratory. In addition, the role of neuroprotective effect of omega-3 might find a clinical application against the hazardous effects among the exposed workers.

\section{Acknowledgment}

I would like to thank Prof. Mohammed Elsakkar for his help in assay of the profile of oxidative stress markers.

\section{References}

Abd El-Rahman M, El-Khadragy MF, Abd-El Hay H et al., (2011): Effect of some cement components on ion contents in different brain areas of adult male albino mice. Journal of Hazardous Materials; 186: 1527-40

Aebi H. (1974): Catalase. In: Bergmeyer HU, eds. Methods of Enzymatic Analysis. New York: Academic Press Inc; 673-684.

Al-Neaimi YI, Gomes JN, Lloyd OL (2001): Respiratory illnesses and ventilator function among workers at a cement factory in a rapidly developing country. Occup Med; 51:367-73.

Bancroft JD and Gamble M (2005). Theory and practice of histological techniques. 5th ed. London Churchill Livingstone; 394-420.

BrahmachariS, Fung YK, Pahan K (2006). Induction of glial fibrillary acidic protein expression in astrocytes by nitric oxide. J Neurosci; 26:4930-4939

BraidyN, Poljak A, Marjo C, et al., (2014): Metal and complementary molecular bioimaging in Alzheimer's disease.Frontier in aging neuroscience; 138 (6): 1-14

Calvert GM, Rice FL, Boiano JM, et al., (2003): Occupational silica exposure and risk of various diseases: an analysis using death certificates from 27 states of the United States. Occup Environ Med; 60:122-129

Chaudhary M, Joshi Dk, Tripathi S, et al., (2014): Docosahexaenoic acid ameliorates aluminum induced biochemical and morphological 
alteration in rat cerebellum. Annals of Neurosciences; 21(1):1-15

Cooper GS, Gilbert KM, Greidinger EL, et al.,(2008): Recent advances and opportunities in research on lupus: Environmental influences and mechanisms of disease. Environ Health Perspect; 116:695-702.

Gutteridge JM (1984): Reactivity of hydroxyl and hydroxyl-like radicals discriminated by release of thiobarbituric acid-reactive material from deoxy sugars, nucleosides and benzoate. Biochem J; 224: 761-767.

Halliwell B (1992): Reactive oxygen species and the central nervous system. J Neurochem; 59: $1609-1623$.

Halliwell B (2006): Oxidative stress and neurodegeneration: where are we now? J Neurochem; 97: 1634-1658.

Halliwell B and Gutteridge JMC (1985): Oxygen radicals and the nervous system. Trends Neurosci; 8: 22-26

Johnstone D and Milward EA (2010b): Molecular genetic approaches to understanding the roles and regulation of iron in brain health and disease. J Neurochem; 113: 1387-1402.

Jomova $\mathrm{K}$ and Valko $\mathrm{M}$ (2011). Importance of iron chelation in free radical-induced oxidative stress and human disease. Cur Pharm; 17: 3460-3473.

Jugdaohsingh R (2007): Silicon and bone health. Journal of Nutrition, Health and Aging; 11(2): 99-110.

Kálmán M(2004): Glial reaction and reactive glia. Adv Mol Cell Biol.;31:787-835

Kawakita E, Hashimoto M, Shido O (2006): Docosahexaenoic acid promotes neurogenesis in vitro and in vivo Neuroscience.;139:991997

Macdonald HM, Hardcastle AC, Jugdaosingh R, et al., (2012): Dietary silicon interacts with oestrogen to influence bone health: evidence from the Aberdeen Prospective Osteoporosis Screening Study. Bone; 50 (3): 681-687.

Manjula R, Praveena R, Clevin RR, et al., (2013): Effects of occupational dust exposure on the health status of portland cement factory workers. International Journal of Medicine and Public Health; 3(3): 192-6

Martin KR (2007): The chemistry of silica and its potential health benefits. Journal of Nutrition, Health and Aging; 11( 2): 94-98.

Meguro R, Asano Y, Odagiri S, et al., (2007): Nonheme-iron histochemistry for light and electron microscopy: a historical, theoretical and technical review. Arch Histol Cytol; 70(1):1-19

Meo SA (2004): Health hazards of cement dust. Saudi Med J.; 25(9):1153-9.

Mesquita SD, Ferreira AC, Sousa JC, et al.,(2012): Modulation of iron metabolism in aging and in Alzheimer's disease: relevance of the choroid plexus. Front Cell Neurosci;6:25.
Michael-Titus AT (2007): Omega-3 fatty acids and neurological injury. Prostaglandins, Leukotrienes and Essential Fatty Acids; 77: 295-300

Mills E, Dong XP, Wang F, et al., (2010): Mechanisms of brain iron transport: insight into neurodegeneration and CNS disorders. Future Medicinal Chemistry; 2( 1):51-64.

Misra HP and Fridovich I (1972): The role of superoxide anion in the autoxidation of epinephrine and a simple assay for superoxide dismutase. J Biol Chem; 247:3170-3175.

Murphy S (2000). Production of nitric oxide by gial cells: regulation and potential roles in CNS. Glia; 29:1-13

Mwaiselage J, Moen B, Bratveit M (2006): Acute respiratory health effects among cement factory workers in Tanzania: An evaluation of a simple health surveillance tool. Int Arch Occup Environ Health; 79: 49-56.

Ohkawa H, Ohishi N, Yagi k (1979). Assay for lipid peroxidation in animal tissue by thiobarbituric acid reactin. Annals of biochemistry; 95:351-8

Parks CG and Cooper GS (2006): Occupational exposures and risk of systemic lupus erythematosus: A review of the evidence and exposure assessment methods in populationand clinic-based studies. Lupus; 15: 728-736.

Pekny M and Nilsson M (2005): Astrocyte activation and reactive gliosis. Glia.;50:427-434

Price CT, Koval KJ, Langford JR (2013): Silicon: A review of its potential role in the prevention and treatment of postmenopausal osteoporosis. International Journal of Endocrinology; volume $2013: 1-6$

Rakic P (2002): Adult neurogenesis in mammals: an identity crisis. J Neurosci.; 22:614-8

Ridet JL, Malhotra SK, Privat A, et al., (1997): Reactive astrocytes: cellular and molecular cues to biological function. Trends Neurosci.; 20:570-577

Rifaai rehab Ahmed, El-Tahawy, Nashwa Fathy, Entesar Ali (2011): Immunohistochemical study on the effect of soft diet and omega 3fortified soft diet on neurogenesis in the rat dentate gyrus and the subventricular zone. Egyptian Journal of Histology; 34(3):528-537

Salem NJR, Litman B, Kim Hy, et al., (2001): Mechanisms of action of docosahexaenoic acid in the nervous system. Lipids; 36, 945959.

Short S and Petsonk EL (1996): Non-fibrous inorganic dusts. In: Harber P, Schenker MB, John R (Eds.). Occupational and Environmental Respiratory Disease. Balmes Mosby; London,: p. 356.

Takahashi S, Hatashita S, Taba Y, et al., (2000): Determination of the spatial distribution of major elements in the rat brain with X-ray fluorescence analysis. Journal of Neuroscience Methods; 100 (1-2): 53-62

Wu J, Wang C, Sun J, et al., ( 2011): Neurotoxicity of silica nanoparticles: brain localization and 
dopaminergic neurons damage pathways. ACS Nano; 5(6):4476-89.

Yang H, Liu C, Yang D, et al., (2009): Comparative study of cytotoxicity, oxidative stress and genotoxicity induced by four typical nanomaterials: the role of particle size, shape and composition. J Appl Toxicol.; 29: 69-78
Yavin E, Brand A, Green P (2002): Docosahexaenoic acid abundance in the brain: a biodevice to combat oxidative stress. Nutr Neurosci; 5: $149-157$.

Zeenat F and Zaidi P (2010): Effects of sodium nitriteinduced hypoxia on cerebellar purkinje cells in adult rats. J Med Sci ; 26 (2):261-266.

\section{الملخص العربي}

\section{دراسه لتاثير الحديد والسيليكون كمكونات للاسمنت علي قشرة كل من المخ والمخيخ في الفئران البيضاء

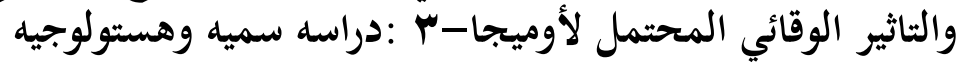

\section{عبيرعبد المنعم شتا' و نهي محمود زهران}

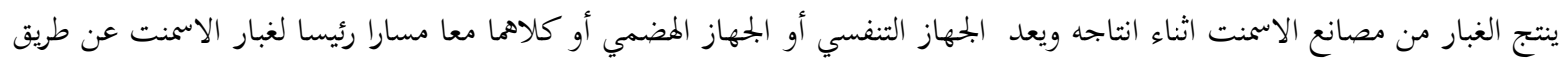

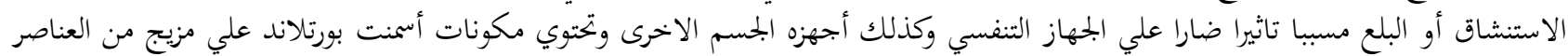

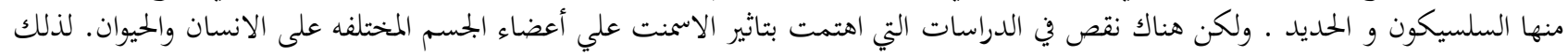

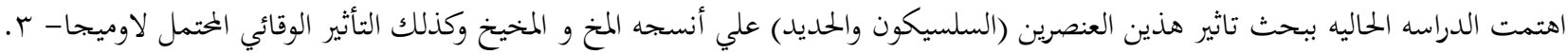

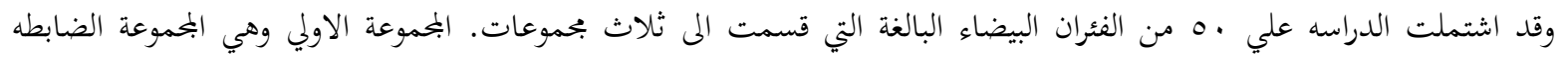

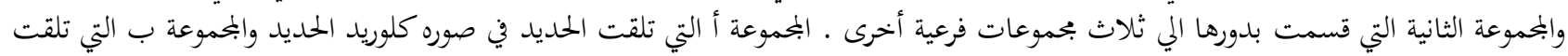

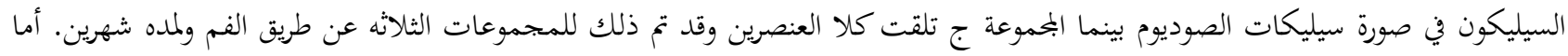

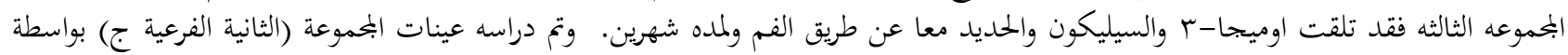
الطاقة المشتتة

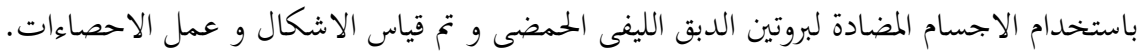

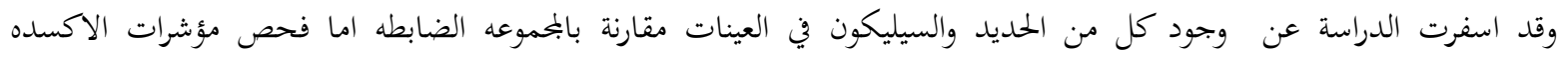

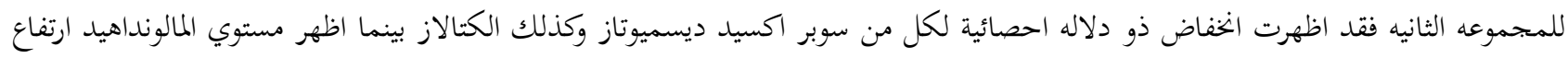

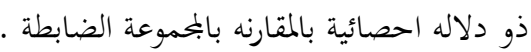

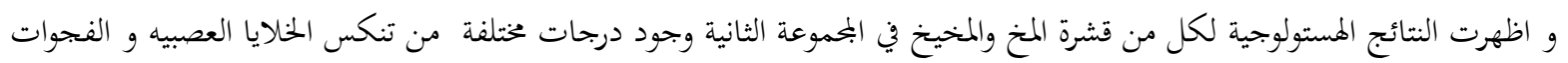

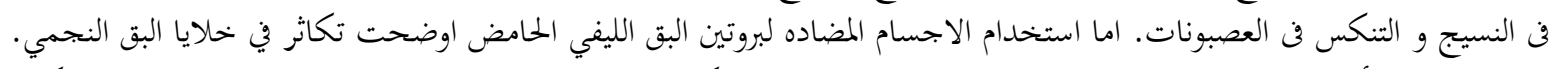

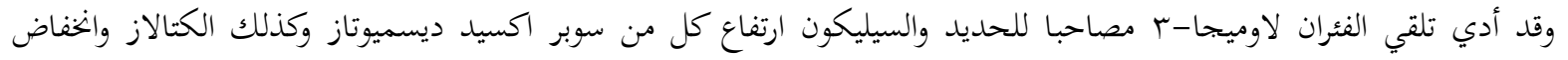

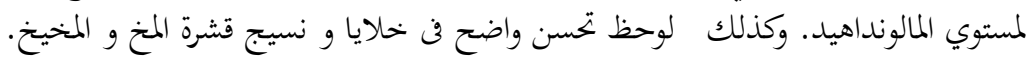

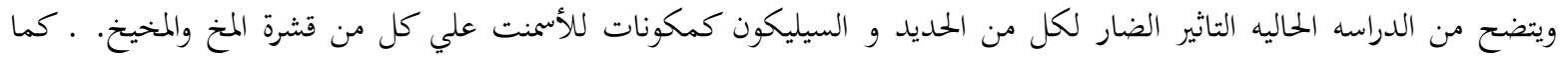

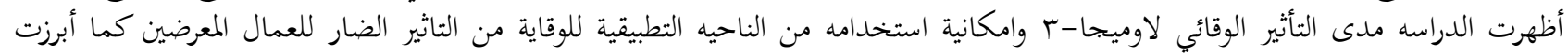

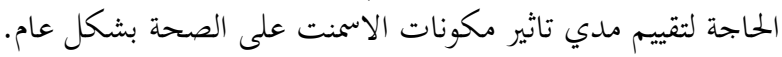

ا قسم الطب الثرعي والسموم الإكلينيكية - كلية الطب - جامعة الإسكندرية r قسم الهستولوجيا والخلايا الحيوية - كلية الطب - جامعة الإسكندرية 